\title{
Enemy escape: A general phenomenon in a fragmented literature?
}

\author{
Julia J. Mlynarek $^{\mathrm{a} \dagger}$, Chandra E. Moffat ${ }^{\mathrm{a} \ddagger \S}$, Sara Edwards ${ }^{\mathrm{b}}$, Anthony L. Einfeldt ${ }^{\mathrm{a}}$, Allyson Heustis ${ }^{\mathrm{ac}}$, \\ Rob Johns ${ }^{c}$, Mallory MacDonnell ${ }^{a}$, Deepa S. Pureswaran ${ }^{d}$, Dan T. Quiring ${ }^{b}$, Zoryana Shibel ${ }^{a}$, and \\ Stephen B. Heard ${ }^{\text {a* }}$ \\ ${ }^{a}$ Department of Biology, University of New Brunswick, P.O. Box 4400, Fredericton, NB E3B 5A3, \\ Canada; ${ }^{b}$ Population Ecology Group, Faculty of Forestry \& Environmental Management, University of \\ New Brunswick, P.O. Box 4400, Fredericton, NB E3B 5A3, Canada; ${ }^{c}$ Forest Insect Ecology, Atlantic \\ Forestry Centre, 1350 Regent Street, P.O. Box 4000, Fredericton, NB E3B 5P7, Canada; ${ }^{\mathrm{d}}$ Forest Insect \\ Ecology, Laurentian Forestry Centre, 1055 Du PEPS Street, P.O. Box 10380, Québec, QC G1V 4C7, \\ Canada \\ * sheard@unb.ca \\ ${ }^{\dagger}$ Present address: Harrow Research and Development Centre, Agriculture and Agri-Food Canada, 2585 \\ County Road 20, Harrow, ON N0R 1G0, Canada \\ ${ }^{\ddagger}$ Present address: Fredericton Research and Development Centre, Agriculture and Agri-Food Canada, 850 \\ Lincoln Road, Post Office Box 20280, Fredericton, NB E3B 4Z7, Canada \\ ${ }^{\S}$ These authors contributed equally to this work.
}

\section{Abstract}

Many populations are thought to be regulated, in part, by their natural enemies. If so, disruption of this regulation should allow rapid population growth. Such "enemy escape" may occur in a variety of circumstances, including invasion, natural range expansion, range edges, suppression of enemy populations, host shifting, phenological changes, and defensive innovation. Periods of relaxed enemy pressure also occur in, and may drive, population oscillations and outbreaks. We draw attention to similarities among circumstances of enemy escape and build a general conceptual framework for the phenomenon. Although these circumstances share common mechanisms and depend on common assumptions, enemy escape can involve dynamics operating on very different temporal and spatial scales. In particular, the duration of enemy escape is rarely considered but will likely vary among circumstances. Enemy escape can have important evolutionary consequences including increasing competitive ability, spurring diversification, or triggering enemy counteradaptation. These evolutionary consequences have been considered for plant-herbivore interactions and invasions but largely neglected for other circumstances of enemy escape. We aim to unite the fragmented literature, which we argue has impeded progress in building a broader understanding of the ecoevolutionary dynamics of enemy escape.

Key words: enemy release, invasions, range expansions, enemy-free space, host shifts, phenological shifts, defensive innovations, predator suppression, mesopredator release

\section{Introduction}

For nearly a century, a central concern of population ecologists has been elucidating how natural populations are regulated. The distinction between exponential (unregulated) and logistic (regulated) growth is emphasized in every first-year biology course, and an enormous literature-both theoretical and empirical-has explored how populations may limit their own growth or are limited by 
competitors, predators, and parasites (e.g., Lack 1954; Russell 1989; Holt and Lawton 1994; Rosenheim 1998). The emphasis on regulation has made conspicuous those cases in which populations undergo rapid growth, or reach unusual levels, in apparent escape from regulation. This is perhaps most obvious during invasions, where species transported outside their natural geographic range establish and undergo rapid population growth - with many species attaining much higher densities in their invaded ranges than in their natural ranges (Keane and Crawley 2002). Because of the enormous ecological and economic costs of invasions, much effort has gone into understanding the mechanisms behind this apparent escape from population regulation. A dominant hypothesis explaining the explosive growth of invasive species is that such growth occurs when (and because) these species are introduced without the natural enemies that regulate populations in their home range (Maron and Vilà 2001; Torchin et al. 2003). This notion has become known as the "enemy release hypothesis" (Keane and Crawley 2002).

The hypothesized importance of enemy release in invasions is mirrored by supposed pathways for escape from natural-enemy regulation in other circumstances (Table 1). For example, the literature on host-race formation and ecological speciation in phytophagous insects identifies "enemy-free space" as a selective advantage for insect individuals exploiting a novel host-with that advantage counterbalancing physiological maladaptation and permitting population growth on the novel host. Escape from enemies has also been identified as a possible result of natural range expansion, shifts in phenology that disrupt life history synchrony with attackers, the evolution of novel defenses, and the suppression (by humans) of predator populations. Despite the similarities between all these hypotheses, they have largely been discussed in separate literatures, which we believe has impeded the general understanding of enemy escape.

In fact, even the terminology associated with escape from enemy regulation varies among hypotheses. For instance, invading species are said to achieve "enemy release", host-shifting herbivores are said to access "enemy-free space", and the suppression of top predators is said to increase densities of intermediate predators through "mesopredator release". Here, we use the umbrella term "enemy escape" to describe any case in which a species undergoes rapid population growth or attains unusual population density in the absence of (or after strong reduction in) enemy regulation. However, we emphasize that the word "escape" should not be taken to imply that it must be an action or change on the part of the victim that

Table 1. Characteristics, outcomes, and paths in the conceptual model (Fig. 1) of the enemy escape scenarios commonly discussed in the current literature (see definitions of the characteristics in the text).

\begin{tabular}{|c|c|c|c|c|c|}
\hline $\begin{array}{l}\text { Escape } \\
\text { circumstance }\end{array}$ & $\begin{array}{l}\text { Instigating } \\
\text { event }\end{array}$ & $\begin{array}{l}\text { Magnitude of } \\
\text { change }\end{array}$ & $\begin{array}{l}\text { Speed of } \\
\text { occurrence }\end{array}$ & $\begin{array}{l}\text { Duration of escape } \\
\text { (and main influence) }\end{array}$ & $\begin{array}{l}\text { Path in model } \\
\text { (Fig. 1) }\end{array}$ \\
\hline Invasions & Extrinsic & Large & Instant & Definitive & Arrow $1 b$ \\
\hline Range expansions & $\begin{array}{l}\text { Extrinsic or } \\
\text { intrinsic }\end{array}$ & Small-large & Many generations & Transient to definitive (extent of expansion) & $\begin{array}{l}\text { Any, depending on } \\
\text { expansion rates, etc. }\end{array}$ \\
\hline Enemy suppression & Extrinsic & Large & Few generations & $\begin{array}{l}\text { Transient to definitive (extirpation vs. } \\
\text { extinction) }\end{array}$ & Arrow $1 \mathrm{a}$ or $1 \mathrm{~b}$ \\
\hline Phenological shifts & $\begin{array}{l}\text { Extrinsic or } \\
\text { intrinsic }\end{array}$ & Medium-large & Many generations & $\begin{array}{l}\text { Transient to definitive (relative } \\
\text { evolutionary rate in enemies vs. victims) }\end{array}$ & $\begin{array}{l}\text { Any, depending on } \\
\text { evolutionary rates, etc. }\end{array}$ \\
\hline $\begin{array}{l}\text { Defensive } \\
\text { innovation }\end{array}$ & Intrinsic & Large & Few generations & Transient (arms races) to definitive & Arrow $2 \mathrm{a}$ or $2 \mathrm{~b}^{a}$ \\
\hline Host shifts & Intrinsic & Medium-large & Many generations & $\begin{array}{l}\text { Transient to definitive (new host: novelty } \\
\text { vs. inaccessibility) }\end{array}$ & Arrow $2 \mathrm{a}$ or $2 \mathrm{~b}^{a}$ \\
\hline
\end{tabular}

${ }^{a} 2 \mathrm{~b}$, or not $2 \mathrm{~b}-$ that is the question. 
breaks regulation. That is true in some cases (for instance, invasions, range expansions, host shifts, and defensive innovation), but in others the change is on the part of the enemy (predator suppression), and change by either victim or enemy may break regulation in still others (phenological shifts).

In this paper, we synthesize literature dealing with these various enemy escape hypotheses. We begin with a simple conceptual model that draws attention to similarities and differences among hypotheses for, and consequences of, enemy escape. Then, in light of this conceptual model we outline each hypothesis and suggest connections between them by comparing their characteristics: the type of instigating event, the magnitude of change, the speed of occurrence, and the duration of escape (i.e., whether escape is transient or definitive; Table 1). Our aim is not to provide a comprehensive review or meta-analysis of enemy escape for any of the separate hypotheses, although we cite such reviews when they are available. Instead, we emphasize similarities and differences among situations in which enemy escape is hypothesized to allow population growth free of previous regulation. Although these hypotheses can involve dynamics operating on very different temporal and spatial scales, they also share common assumptions and mechanisms. We believe that attention to common assumptions and mechanisms can help the study of enemy escape transcend idiosyncratic details of particular species and study systems - or perhaps even more usefully, guide us in determining which of those details might influence the likelihood and consequences of enemy escape. We hope that the connections we draw between hypotheses and mechanisms of enemy escape can better inform future studies of the ways enemies regulate, and sometimes fail to regulate, natural populations, and of the consequences for natural communities when regulation fails.

\section{A conceptual model of enemy escape}

We begin our review by outlining a general and intuitive conceptual model that can be applied to the process of enemy escape. Under any hypothesis of enemy escape, we argue the first step is an ecological or evolutionary "instigating event" that disrupts the regulatory influence of enemies on populations of their victims (Fig. 1). This event can be extrinsic to the enemy-victim system (i.e., an outside pressure brought to bear on the enemy-victim system; Fig. 1, arrow 1) or it can be intrinsic to that system (i.e., an adaptation evolved by the victim that changes its interaction with the enemy; Fig. 1, arrow 2). In either case, the victim population becomes free to expand in the absence of regulation by enemy attack. This escape, however, may be short-lived or long-lasting. If the enemy is able to "catch up" with its host, either ecologically or evolutionarily, then enemy escape is transient (Fig. 1, arrows 1a and 2a), and enemy-victim dynamics may even be oscillatory (with regulation, escape, and re-regulation, potentially repeated-either via repeating ecological changes or via a coevolutionary arms race). In contrast, if the enemy cannot "catch up", enemy escape is "definitive" (Fig. 1, arrows $1 \mathrm{~b}$ and $2 \mathrm{~b}$ ): the victim remains free of the constraints of population regulation and (or) selective pressure from the enemy in question. Definitive escape can result in shifts in victim life history trade-offs (e.g., Herms and Mattson 1992), such as reduced allocation of resources to defense. In turn, this may permit evolution along pathways previously constrained by enemy pressure, such as the evolution of increased competitive ability (EICA; Blossey and Notzold 1995). Other evolutionary trajectories are obviously possible (Herms and Mattson 1992), including divergence and ultimately speciation triggered when released individuals begin to exploit a novel or expanded ecological niche (i.e., "escape and radiation"; Berenbaum 1983; Farrell et al. 1991; Thompson 1994; Edger et al. 2015). The evolutionary consequences of enemy escape are rarely considered outside of plant-herbivore co-evolution or (plant) invasion biology, and yet should be expected in any population experiencing enemy escape.

\section{Two core assumptions}

All of the enemy escape scenarios we describe share two core assumptions, and escape and its consequences can only occur if both are met. First, if populations are to grow by escaping regulation by 


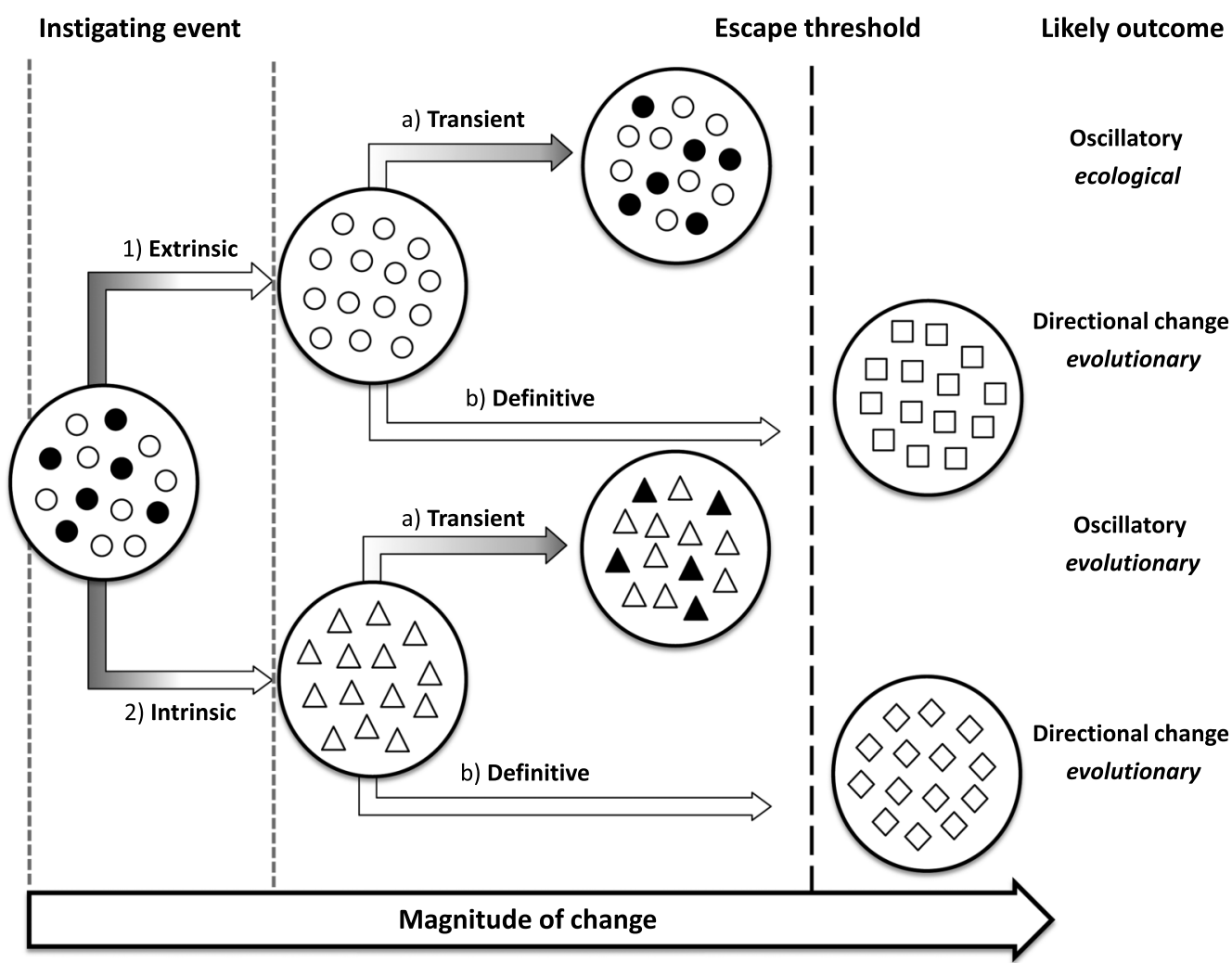

Fig. 1. Conceptual model of enemy escape. Instigating events that lead to enemy escape can be (1) extrinsic or (2) intrinsic. The magnitude of change influences whether the enemy escape will be (a) transient (or the enemies will catch up) or if the change in the species reaches an escape threshold enemy escape will be (b) definitive (the original enemies will not affect a species anymore) leading to the likely outcomes for each of the pathways. Open symbols = individuals of a species not affected by an enemy; filled symbols = individuals of a species affected by an enemy; darker portion of gradient arrows = populations that are affected by enemies; lighter portion of gradient arrows $=$ those that have escaped enemies; white arrows $=$ enemy escape.

their natural enemies, then an obvious, but critical, assumption is that those populations, before they escape, are effectively regulated by those enemies. Second, that regulation must not be unbreakable, i.e., some possible ecological or evolutionary event must be powerful enough to disrupt regulation. In addition to these core assumptions, the hypothesis of enemy escape in each circumstance makes additional assumptions-some unique to a single circumstance, others shared by two or more. We examine these during discussion of each circumstance.

The assumption of pre-escape regulation is essentially an assumption that populations are under topdown regulation. Of course, this will not be true for all species at all times, but for the enemy escape hypotheses to be important to our understanding of natural communities, top-down regulation must at least be common. The question of how often animal and plant populations are regulated by natural enemies has generated much debate (Murray 1999), especially during the mid-20th century when there was a vigorous debate between researchers postulating that regulation by biotic agents, including enemies and competitors, was common (e.g., Lack 1954) and those arguing that it was not (e.g., Andrewartha and Birch 1954). This debate was long-lasting partly because of the difficulty of gathering adequate data to test hypotheses about population control (Murdoch 1994). For example, the probability of detecting density dependence, and thus potential regulation, increases with the 
length of population density time series data, but long time series are rare. As an illustration, Woiwod and Hanski (1992) were able to detect density dependence in time series for $69 \%$ of 94 aphid and $29 \%$ of 263 moth species. However, the frequency of density dependence rose to $84 \%$ and $57 \%$, respectively, when short time series ( $<20$ years) were excluded from the analysis. Unfortunately, these analyses could not distinguish regulation by natural enemies from regulation by other density-dependent agents, such as intraspecific competition.

It is now generally agreed that enemies regulate populations of many species at many, but not all, times. For instance, many marine invertebrates are under clear limitation by predator attack (e.g., Frid and James 1988; Beal et al. 2001). Top-down trophic cascades suppress population densities in many freshwater pelagic systems (e.g., Brett and Goldman 1997), and this pattern seems to extend to a wide variety of ecosystems (Borer et al. 2006). Although population-level studies of regulation are much fewer in plants than for animals, attack by natural enemies frequently limits plant reproduction, survival, and (or) population growth (Maron and Crone 2006; Ancheta and Heard 2011). Finally, the keystone predator/herbivore concept (Paine 1969) assumes population regulation by enemies, and the frequent labelling of species as keystone predators or herbivores (e.g., Clemente et al. 2010; Davenport and Chalcraft 2013; Freed et al. 2014) provides further evidence that enemy regulation is common.

The assumption of breakable regulation implies that the instigating event must be significant enough that the enemy cannot immediately compensate. The event must be large enough in magnitude, or sudden enough, that regulation is broken and population densities of the victim can increase. For example, for a victim to escape enemy regulation by range expansion, it must disperse far or quickly enough that the enemy is left behind; or if a victim evolves novel defense traits, enemies must not be able to coevolve quickly enough to counter them. We return to this issue when we discuss the relevant circumstances, and also when we discuss factors influencing the expected duration of escape in general.

\section{Circumstances of enemy escape}

We turn now to the various ecological and evolutionary circumstances in which enemy escape has been discussed-invasion, range expansion, host shifts, and so on. Each can be thought of as a hypothesis connecting events to population expansions. To organize our discussion, we will discuss these in turn and largely separately, although of course there are points of overlap. We point out some important areas of overlap in what follows, but do not attempt to catalogue them exhaustively.

\section{Escape in invasions}

The enemy release hypothesis (ERH; Keane and Crawley 2002) predicts that escape from co-evolved, specialist natural enemies can facilitate success of a species introduced to a novel area. Introduced species that are successful in building population density or expanding in range are generally termed "invasive", and we adopt that terminology while recognizing that the semantics of introductions and invasions is somewhat controversial. The ERH has been described as the "most straightforward and intuitively appealing explanation for the rapid establishment and proliferation of non-indigenous species" (Colautti et al. 2004, p. 721). There are many other hypotheses, not mutually exclusive with the ERH (Lowry et al. 2013), but these are outside the scope of our review.

In invasions, the ecological change is large in magnitude and occurs instantaneously with the introduction (Fig. 1, arrow 1). The premise of the ERH is that the invading species may encounter generalist enemies in its new range, but not specialists that have evolved to exploit it efficiently. Release from the ecological constraints imposed by such specialist enemies allows the former victim to increase in both individual vigor and population size, and this is held to explain invasiveness 
(Maron and Vilà 2001; Keane and Crawley 2002; Torchin et al. 2002, 2003; Colautti et al. 2004; Meijer et al. 2016). However, Gillett (1962) proposed that whenever any species reaches high abundance, the inevitable outcome is the evolution of coevolved enemies (presumably specialists) that decrease host vigor and reduce population size. This suggestion has an interesting implication: that enemy escape should be temporary (Fig. 1, arrow 1a), as new specialist enemies evolve to exploit large invasive populations. The time required, however, may be long (Table 1).

In addition to assuming top-down regulation in the native range, the ERH makes several assumptions that are perhaps best seen as a decomposition of the assumption that native-range regulation is "breakable". It assumes that co-evolved, specialist natural enemies do not typically accompany the invader into its new range; that host shifts of specialist natural enemies (endemic to the new range) to the invading taxon are unlikely, or at least slow (Keane and Crawley 2002); and that generalist enemies in the new range are not able to regulate population dynamics of the invader. Considering these additional assumptions makes it obvious that the ERH can be considered at two levels: as a hypothesis to explain high densities of invasive species in general, or as a hypothesis to explain the success of a particular invasive species. For the general ERH, these assumptions need not hold universally, although they must hold frequently. For a species-specific ERH, each assumption must hold.

Across taxa, the enemy release hypothesis is sometimes supported, and sometimes not (reviewed in Torchin et al. 2003; Colautti et al. 2004; Liu and Stiling 2006; Meijer et al. 2016). General patterns can be difficult to infer given the different approaches employed to test the ERH within and between taxonomic groups, and even within single studies support for the ERH may vary based on which types of variables are measured (Meijer et al. 2016). A good example of a population-level test of the ERH was provided by Jongejans et al. (2006) for the nodding thistle Carduus nutans L. In its native range, removal of native insect seed herbivores increased population growth more than 2.5-fold, supporting the core assumption of top-down regulation and thus lending support for the ERH where this species invades the Americas and Oceania. Similarly, the Asian tiger mosquito Aedes albopictus (Skuse) shows reduced infection by its gut parasite Ascogregarina taiwanensis Lein \& Levine when invading new sites, providing it a competitive advantage over the native mosquito Ochlerotatus triseriatus (Say) (Aliabadi and Juliano 2002). There are also, however, many studies in which data do not support the ERH (review for plant-insect systems: Meijer et al. 2016).

\section{Escape in natural range expansions and at range edges}

If enemy escape is likely during invasions, it is also an obvious possibility during natural range expansions (e.g., Coon and Martin 2014) - but one for which the literature is less voluminous (Svenning et al. 2014). In this case, the main assumption is that monophagous natural enemies cannot expand faster than their hosts, and may instead lag behind (e.g., Phillips et al. 2010; and developed in an island-biogeographic context by Gravel et al. 2011). If so, then enemy escape could facilitate range expansion by increasing growth and reproduction or decreasing mortality, for victims at range margins.

Not all enemies are expected to lag the expansion of their victims, or at least, not to the same degree. Large expansion lags, and thus enemy escape, are particularly likely if victim populations at range edges are smaller (Gaston 2009), less fit, or more patchily distributed (e.g., Sexton et al. 2009). However, the relative vagility and longevity of enemy and victim may also influence the expansion lag. For example, we might predict little or perhaps transient escape (Fig. 1, arrow 1a/2a) through range expansion for trees under attack by insect pests, as trees are both slower to produce dispersers (seeds) and less proficient at movement than their attackers. In contrast, for annual plants under attack by soil pathogens or root-boring nematodes, range expansion might bring substantial and lasting escape (Fig. 1, arrow 1b/2b). The degree to which the enemy depends on the range-expanding 
victim should also matter: lags may be enforced for monophagous enemies, but generalists may already be present beyond a victim's range. Intermediate cases are certainly possible, although we are not aware of any studies exploring effects of degree of specialization on expansion lags. The magnitude of change for enemy escape through range expansions should be considered as a continuum (Table 1).

Enemy escape may be harder to recognize during natural range expansion than during invasions. This is because, for a variety of reasons, population densities at range margins are often expected to be lower than for range-central populations. This is the "abundant centre hypothesis" (Brown 1984; but see Abeli et al. 2014). When ranges are expanding, range-margin populations may simply not have had time for population growth. They may also be maladapted to the local abiotic environment, either because selection has not yet had time to act there or because gene flow from the range centre overpowers local selection (Kirkpatrick and Barton 1997; but see Holt et al. 2003). This means that we should think of enemy escape as allowing range-margin populations to be larger than they would be under "normal" enemy attack, not necessarily larger than range-central populations. For this reason, studies of enemy escape in range expansions have focused on direct tests of the hypothesis that populations at expanding range margins are under lower per-capita enemy attack than populations in the historic range (Phillips et al. 2010).

There is support for the expansion-escape hypothesis in case studies involving both plants and animals. In western Europe, yellow goat's beard (Tragopogon dubius Scopoli) is expanding its range northward. It performs better in soil inoculated with range-margin rhizosphere microbes than with range-central microbes (van Grunsven et al. 2010), which likely reflects escape from pathogens at range margins. (A pattern of increased individual performance is a necessary but not sufficient condition for population size increase.) Similarly, a lungworm parasite lags behind the expansion of cane toad (Rhinella marina (L.)) in its Australian invasive range (Phillips et al. 2010).

Enemy escape need not be confined to the margins of actively expanding ranges. Even stationary range margins are likely to have lower population densities, potentially reducing enemy population growth rates below those needed for local persistence. In addition, asymmetric immigration by enemy individuals arriving from the range centre but not from beyond the range margin could reduce the likelihood of enemies persisting as sink populations at range margins. Such effects could favour larger equilibrium (victim) range sizes (e.g., Sexton et al. 2009), not just more rapid range expansion. Data consistent with reduced enemy pressure at stationary range margins have been gathered primarily in plant systems. For example, in the North American common milkweed (Asclepias syriaca L.), northern and southern range-limit populations experience less leaf damage and lower attacking insect diversity than populations at the centre of the range (Woods et al. 2012). However, not all systems will have such simple patterns of escape at range margins. For instance, the most northern populations of European juniper (Juniperus communis L.) escape seed predation by a chalcid wasp-but so do several range-interior populations, and overall position within the range does not predict seed losses to enemies (Garcia et al. 2000).

Natural range expansions differ from invasions in several ways that may be relevant to the likelihood and duration of enemy escape. Most obviously, invasions (by definition) are human-assisted, and some important routes for invading propagules may make co-invasion by enemies more likely than for natural range expansions over similar distances. In contrast, natural range expansions usually cover distance much less quickly and with fewer and shorter jumps across inhospitable matrix habitat, which might favour co-expansion by enemies. There is an obvious question: In what circumstances do each of these opposing influences outweigh the other? Because tests of the expansion-escape hypothesis lag far behind those of the invasion-release hypothesis, settling this question will have to wait for a much larger set of empirical studies. Along similar lines, we are unaware of analyses testing for the 
effects of the rate of range expansion (or analogously, invasion distance) on the frequency of enemy co-expansion or co-invasion.

Answering questions about enemy escape at range margins is becoming increasingly important because range shifts, including poleward and other range expansions, are both predicted and documented as a consequence of global climate change. Enemy escape at range margins could facilitate climate-driven range shifts (Morriën et al. 2010) and thus reduce the risk of extinction as a result of climate change, but this is by no means a sure thing and the likely duration of such escape is unknown. Some studies suggest that escape may be fleeting, with enemies rapidly catching up (e.g., Coon and Martin 2014), but in other cases it may be persistent-especially when escape occurs at stationary range margins (e.g., Woods et al. 2012; Lakeman-Fraser and Ewers 2013).

\section{Escape via host shifts}

Species do not have to move in space to escape their enemies. Parasites (including herbivorous insects and parasitoids) often have specialized diets, but over evolutionary time frequently adapt by adding new hosts into their diets (Fig. 1, arrow 2). Following such a "host shift", the parasite may continue as a single lineage using a broader diet, or may undergo a process known as host-associated differentiation to yield a pair of new diet specialists (Stireman et al. 2005; Janz 2011). Host shifts seem to involve selection favouring alleles that drive attack on novel hosts, despite the fact that the parasites are likely to be better adapted to exploiting the ancestral hosts with which they have long evolutionary histories. This paradox can be explained if individuals feeding on novel hosts experience reduced rates of enemy attack. This is usually described as the novel host offering "enemy-free space" (Jeffries and Lawton 1984; Berdegue et al. 1996), although the use of "free" is somewhat misleading because escape is rarely, if ever, absolute. Early discussions of this process recognized that enemy-free space could result not just from host shifts but also from behavioural, morphological, habitat, or other changes (Jeffries and Lawton 1984; Berdegue et al. 1996). However, the term has become most strongly associated with host shifts of herbivorous insects (Murphy et al. 2014), by way of its important position in a burgeoning literature on host shifts and the consequent host-associated differentiation and speciation of insects (e.g., Berlocher and Feder 2002; Stireman et al. 2005). Our review will stress insect herbivores for this reason, but we remind readers that what we say about herbivores should apply to other parasites too.

The population-dynamic consequences of enemy-free space (in the context of host shifts) may not be easy to detect, for the very reason that enemy-free space is of interest in the first place: its influence in increasing individual fitness and thus population size will act in opposition to maladaptation to the novel host. Escape from enemies might exactly counterbalance that maladaptation, outweigh it, or merely reduce the disadvantage. As a result, there is no simple prediction for whether the growth rate and size of herbivore populations should be larger or smaller on the novel host than on the ancestral host (contra hypothesis 2 of Berdegue et al. 1996). Instead, the relevant question here is: Are herbivore populations larger on the novel host than they would have been in the continued presence of the enemies? This must usually be tested indirectly, with measurements of enemy-induced mortality rates on ancestral and novel hosts (Heard et al. 2006).

In order for host shifts to generate enemy-free space, enemy search or attack efficiency must be lower on novel hosts than on ancestral hosts. This may occur in one of two ways. First, the novel host may provide intrinsic protection against enemies: it may be harder for those enemies to locate, it may have architecture making search difficult (such as complex or hairy foliage; Ballabeni et al. 2001), it may provide sequesterable defensive chemicals (e.g., Denno et al. 1990), or it may provide physical refuge (such as plant organs large enough for larvae to tunnel beyond the reach of parasitoid ovipositors; e.g., Feder 1995). Escape should then be definitive (Fig. 1, arrow 1b). Under this view, a pattern of 
consistently lower attack on novel hosts would suggest that the availability of enemy-free space acts like a filter, dictating on which novel hosts herbivore populations persist long enough to evolve specialization. Alternatively, the novel host may provide transient escape (Fig. 1, arrow 1a) simply because it is novel: the enemy may be perfectly able to locate and attack victims on the new host, once selection has had time to act on behavioural or other traits necessary for it to do so (Singer and Stireman 2005). This hypothesis suggests that novelty could ease shifts onto any alternative host.

Enemy-free space following host shifts has been documented in a number of systems. A classic example involves the apple maggot fly Rhagoletis pomonella (Walsh), which colonized cultivated apple as a novel host after the introduction of apples to the midwestern USA. Apple fruits are much larger than fruits of the ancestral hosts (hawthorns, Crataegus spp.), and the consequence appears to be dramatically lower parasitoid attack on the novel host (Feder 1995). Evolutionary shifts in microhabitat may also yield enemy-free space. For instance, leafmining heterarthrinid sawflies evolved from externally feeding ancestors (Leppänen et al. 2012, 2013) and left behind a complex of parasitoids ill-suited to exploiting victims hidden in plant tissue. However, many fewer data are available for microhabitat shifts, and it is therefore unclear whether they should generate enemy-free space as commonly, or for as long, as host shifts do for herbivores and other parasites.

\section{Escape via phenological shifts}

Phenological synchrony, or the temporal co-incidence of development (van Asch and Visser 2007; Singer and Parmesan 2010), is crucial to fitness for organisms that depend on victim species (or developmental stages) that are only temporarily available. For example, among herbivorous insects, many folivores attack newly expanding leaves and thus need to be synchronised with budburst, whereas specialist seed predators need to match the seed set of their hosts. When the phenology of either the enemy or the victim shifts, the result may be enemy escape (Bewick et al. 2016) (or, of course, other consequences including extinction; Cahill et al. 2012).

Most of the recent data on phenological escape from natural enemies have been collected for plants that escape herbivory by altering the timing of vulnerable stages in their life cycle, or for herbivorous insects that similarly escape their predators and parasitoids (Chuine 2010; Santos et al. 2013). The implications of phenological escape have been discussed for insect population dynamics (Hunter and Elkinton 2000; Bewick et al. 2016), including outbreaks (van Asch and Visser 2007), and for the fitness of plant populations under herbivore attack (Russell and Louda 2004).

Phenological shifts can occur through either extrinsic (Fig. 1, arrow 1) or intrinsic (Fig. 1, arrow 2) pathways. Most obviously, selection (via the intrinsic pathway) can favour changes in the timing of critical events in victim life cycles because such changes allow escape in time from their natural enemies. For instance, variation in budburst phenology has been shown to protect against herbivory (Tikkanen and Julkunen-Tiitto 2003), and in the subalpine wildflower Ipomopsis aggregata (Pursh) plants with delayed flowering experienced lower seed predation (Freeman et al. 2003). Phenological traits are often highly heritable but also have high variability within and among populations (van Asch and Visser 2007), which suggests the potential for rapid response to selection (Chuine 2010). Of course, phenological matching or mismatching will also exert selection on enemies, for whom synchrony is directly related to food abundance (Visser and Both 2005). Selection on enemies should favour tracking of victim phenology and so lead to an evolutionary arms race in time-with many possible outcomes, among them transient rather than definitive escape (Fig. 1, arrow 2a). It is not clear, however, whether phenological traits should evolve more quickly for enemies or victims. If phenological traits evolve more quickly for victims (because selection is stronger to avoid mortality than simply to obtain a meal; Dawkins and Krebs 1979; Both et al. 2009), we would expect phenological escape to be long-lasting. However, this assumes equal generation times, and at least for herbivores 
exploiting long-lived perennial hosts, phenological evolution may actually be faster in the enemies making phenological escape transient at best.

Phenological shifts can also result from ecological events (Fig. 1, arrow 1) such as climate change (van Asch and Visser 2007; Bewick et al. 2016). Climate change will affect enemy-victim synchrony when the phenologies of enemy and victim respond to the same cues, but do so differently, or when enemy and victim respond to different cues. When both species respond similarly, the enemy-victim interaction may be unchanged, as is predicted for the oak-winter-moth interaction in which oak budburst and caterpillar development both advance in warmer temperatures (Buse et al. 1999). Such parallel responses may prove to be the exception rather than the rule. In the winter moth system, for instance, great tits that prey on winter moth caterpillars may not be able to advance egg lay sufficiently to maintain synchrony with peak caterpillar abundance, and as a result tits may suffer while the caterpillars benefit (Buse et al. 1999). Phenological shifts could even bring intensified attack rather than escape, especially when victim species become available to new enemies: such potential increases in the severity of herbivory are among predictions for plant-herbivore interactions under climate change (Karban 2007; Forrest and Miller-Rushing 2010; Visser et al. 2010). However, we would hypothesize that decreases in attack would be the most common outcome simply because selection should have optimized phenological matching before the ecological events that disrupt it.

\section{Escape by defensive innovation}

When a population is under enemy attack, individuals expressing the most effective defensive traits have a selective advantage over their conspecifics. Assuming heritable variation, such populations are expected to evolve enhancements to existing defenses or to evolve novel defenses. The result is reduced likelihood and (or) impact of enemy attack on adapted individuals, and (when adaptations go to fixation) possibly on entire populations. Such population-wide enemy escape could presumably disrupt the regulation of victim population dynamics.

Studies of victim response to defensive innovation have focused on physical and chemical defenses, especially in animals and plants, respectively; for example, antipredator armor in molluscs (Vermeij 1987), or toxins, feeding deterrents, latexes, etc. in plants (Ehrlich and Raven 1964; Berenbaum 1983; Farrell et al. 1991). However, many other forms of defense are possible, including parental care (Andersson and Waldeck 2006), crypsis (e.g., Lloyd et al. 2006; Lichter-Marck et al. 2015), thanatosis ("playing dead" or "playing possum"; e.g., Miyatake et al. 2004), and various protective behaviours (e.g., schooling in fishes, Magurran 1990). Any of these could, in principle, facilitate enemy escape.

The literature on defensive innovation and its consequences is almost entirely evolutionary in scope, with very few studies having tested for changes in victim population sizes following defensive innovation (but see Farrell et al. 1991) - despite the fact that this is an important assumption behind the idea that defensive innovation can subvert enemy regulation. We suspect there are two major reasons for this. First, population-dynamic consequences of defensive innovation may be considered too obvious to need testing. However, even if benefits of defensive innovation for individual fitness are axiomatic, effects at the population level are not (see "Two core assumptions", above). Second, comparisons of pre- and post-innovation population dynamics are difficult because of the historical nature of the question. One might use phylogenetic methods to reconstruct ancestral states of defensive characters (e.g., Futuyma and Agrawal 2009; Weber and Agrawal 2014), or of course one can observe them directly from the fossil record (Kelley et al. 2003). Estimating pre-innovation population sizes, though, is challenging. Fossil-based estimation is very difficult and sometimes involves assumptions of unchanging enemy-victim interactions to infer higher trophic level densities from better preserved lower trophic levels (e.g., Jeppesen et al. 1996). Alternative methods based on coalescence in DNA sequence data have been developed (e.g., Drummond et al. 2005) but make many assumptions and 
are unlikely to be effective very deep in time. An alternative is to use the comparative method, inferring the effects of defensive innovation from patterns of population size across lineages possessing and lacking a given innovation. It is, however, challenging to identify enough such lineages for powerful comparisons without having other ecological or evolutionary differences confounded with the innovation in question.

Most studies of escape through defensive innovation have focused on its evolutionary consequences, especially the possibility of ensuing diversification. This emphasis can be traced to an influential paper on co-evolution between plant chemical defenses and butterfly herbivores (Ehrlich and Raven 1964). In Ehrlich and Raven's framework, defensive innovation allowing enemy escape is hypothesized to represent a key innovation providing access to a new adaptive zone and, as a result, spurring diversification. This process is now referred to as "escape and radiation" (e.g., Berenbaum 1983; Thompson 1994). Many, but not all, key innovation hypotheses connect increased speciation rates, or decreased extinction rates, to larger population sizes (Heard and Hauser 1995), and so it is surprising that population-dynamic consequences of enemy escape are not seen as a critical step in the logic of escape-and-radiation scenarios (except see Farrell et al. 1991).

An important question about escape through defensive innovation is: How long should it last? When victims escape their enemies by evolving new defenses, selection should then favour counteradaptation by enemies to overcome those defenses. For example, many plant lineages have evolved latex or resin canals, and in doing so have dramatically reduced attack by herbivorous insects (Farrell et al. 1991). Counteradaptations (such as the behaviour of cutting canals and feeding distal to the disruption; Dussourd and Denno 1991; Dussourd 2009) are known, and in at least some plant-insect interactions the counteradaptations evolve quite quickly after the defense (Becerra 2003). Canal-cutting and other counteradaptations should be strongly favoured when they occur, and this suggests that enemy escape should be transient (Fig. 1, arrow 2a), rather than definitive (arrow 2b). Indeed, the popular "Red Queen" metaphor for victim-enemy coevolution (van Valen 1973) suggests short-term escape, if any: Lewis Carroll's Red Queen ran as fast as she could to stay in the same place, not to get ahead (Carroll 1871). Surprisingly, though, for plants with latex canals enemy escape appears to have persisted on very long timescales (likely 10-180 million years; Farrell et al. 1991). This may be in part because most canal-cutters remain specialists on one canal-bearing lineage rather than host-shifting to achieve broad host range (Dussourd 2009). Perhaps the duration of enemy escape depends on the effectiveness and degree of novelty of the defensive innovation, with exceptional and qualitative advances like the acquisition of latex canals conferring much longer lasting escape than quantitative improvements in existing defenses. To our knowledge, this hypothesis is completely unexplored.

It is at least a hypothetical possibility that enemy escape could result from the evolution of reduced enemy virulence rather than increased victim defense. Selection for reduced virulence is expected for many host-pathogen interactions, depending on the net effect of virulence on parasite net reproductive rate (Ewald 1994; Alizon et al. 2009). The result of reduced enemy virulence could be the relaxation of enemy regulation and thus enemy escape-or it could be the evolution, in response, of reduced defenses by the victim.

\section{Escape through enemy suppression}

Most mechanisms of enemy escape involve distributional or evolutionary change in a victim population, but escape is also possible when enemy populations are removed or suppressed by human activity (or, of course, by other means). Enemies, especially when they are large-bodied predators, may be suppressed directly by exploitation (hunting or fishing) or through bounties and culls, or indirectly by habitat alteration or many other mechanisms (Wroe et al. 2004; Braje and Erlandson 2013; Fig. 1, arrow 1). Although the idea that human intervention to remove predators will benefit prey 
populations is very old, enemy suppression has recently garnered a great deal of attention due to humanity's role in the Earth's sixth mass extinction (Wake and Vredenburg 2008; Barnosky et al. 2011) and to growing awareness that harvesting has reshaped many food webs in fisheries and other systems (Pauly et al. 1998). This has led to extensive literature testing the hypothesis that the suppression (or extinction) of higher trophic level species is the primary driver increasing the success of lower trophic level species across terrestrial and marine environments (e.g., Pauly et al. 1998; Prugh et al. 2009; Estes et al. 2011).

The effects of enemy suppression on victims and ecosystems have been given a variety of labels, including "prey release" (e.g., Fung et al. 2015), "trophic cascades" (e.g., Hairston et al. 1960), "mesopredator release" (e.g., Soulé et al. 1988), "trophic downgrading" (e.g., Estes et al. 2011), and "fishing down the food web" (e.g., Pauly et al. 1998). Enemy suppression of any intensity might have measurable effects on victim populations, but escape through enemy reduction will be most closely analogous to the other mechanisms we review when enemies become severely depleted, extirpated, or extinct.

At first blush, the enemy suppression hypothesis may seem the simplest of all enemy escape hypotheses. This is because escape can occur without any other change in the victim's traits or habitat-that is, unconfounded with changes in geographic range (as in escape through invasion), resource use (escape through host-shifting), climate (escape through phenological shift), and so on. It also does not require that enemies be co-evolved diet specialists. However, complexity arises because in many or most cases, enemy suppression accompanies other human influences on landscapes and ecological communities.

Although there has been a long history of experiments testing for top-down regulation of population dynamics in food chains (especially in aquatic systems; Hrbacek et al. 1961; Carpenter et al. 1987), the enemy suppression hypothesis as we cast it here first received widespread attention with respect to the global phenomenon of increasing densities of mid-sized vertebrate consumers (mesopredator release; review: Prugh et al. 2009; Ritchie and Johnson 2009). For example, Crooks and Soulé (1999) found that the occurrence and abundance of a top predator (coyote, Canis latrans Say) decreased in smaller forest fragments, with concomitant increases in the densities of mesopredators (fox, opossum, raccoon, skunk, and feral cat). Many similar studies demonstrate victim responses following the incidental or intentional removal of predators in vertebrate-dominated terrestrial and marine systems (Pauly et al. 1998; Prugh et al. 2009; Estes et al. 2011); for instance, Myers et al. (2007) found that as abundances of 11 great whales species decreased, populations of smaller elasmobranchs increased. Studies of predator suppression can be correlative or experimental (primarily in the form of predator exclusion experiments) and may take advantage of spatial variation in predator populations, as in cases where human activities have removed predators from some regions but not others (Vance-Chalcraft et al. 2007). Interestingly, a number of studies suggest that the phenomenon is generally reversible by the reintroduction or addition of enemies to experimental systems (review: Rogers and Heard 2000).

Support for the enemy-suppression hypothesis as a mechanism of mesopredator increase is not unanimous, however. For the canonical coyote-mesopredator system, for instance, Prange and Gehrt (2007) found that neither raccoons nor skunks suffered mortality or exhibited predator avoidance in response to coyotes-in contrast to the results of Crooks and Soulé (1999). Victims may fail to respond to enemy removal when they have specialized defenses or use different structural niches from their enemies (review: Ritchie and Johnson 2009). In these cases, enemy escape does not occur because the core assumption of top-down regulation is violated: there is no suppression by enemies to be escaped. Furthermore, the predictive ability of the enemy suppression hypothesis can be limited by the ecological context of a particular enemy-victim interaction. For example, the addition of a top consumer may benefit particular victims by reducing the populations of their competitors (Ellis et al. 2007). This highlights a potential bias in the evidence supporting the enemy escape hypothesis: in 
systems with complex trophic structures, most studies address population responses of the most apparent victims after enemy removal has occurred-and these are the very ones likely to have benefited from enemy escape. The responses of other, lower abundance victims in the system are less likely to be studied. Finally, context matters in another way: depending on the presence or abundance of other species farther up the food chain, a given species might be the suppressed enemy in one system and the escaping victim in another (Roemer et al. 2009). For example, although many studies deal with coyote suppression with subsequent escape by smaller predators such as skunks and raccoons (e.g., Crooks and Soulé 1999), in less impacted ecosystems coyotes can be a mesopredator that can escape when wolves (Canis lupus L.) are suppressed (Berger and Conner 2008).

We have focused here on anthropogenic enemy suppression, but it is worth pointing out that expectations are exactly the same in cases where enemies are reduced or extirpated by other forces. We might expect enemy escape following mass extinctions, for instance, if species at higher tropic levels are more vulnerable. As an example, enemy escape with increasing prey population size has been implicated in the dramatic diversification of crinoids following the Late Devonian mass extinction affecting ammonoids and jawed fishes (Sallan et al. 2011).

\section{Do population outbreaks fit the "enemy escape" mould?}

We suspect that most readers will be quite comfortable with the notion that common ground underlies the six "circumstances of enemy escape" considered so far. We now push the envelope a bit, to ask whether population outbreaks and oscillations can be usefully viewed through the same lens.

Many organisms undergo either regular or irregular population oscillations, and many of these oscillations are accompanied by changes in the intensity of enemy attack. We know a tremendous amount about ecological mechanisms that can, in principle, produce outbreak dynamics. Perhaps surprisingly, though, even for such iconically outbreaking/oscillating species as snowshoe hare (Lepus americanus Erxleben) and eastern spruce budworm (Choristoneura fumiferana (Clemens)), substantial uncertainty remains as to which mechanisms actually drive dynamics in the field (Ginzburg and Krebs 2015; Pureswaran et al. 2016). We believe that an enemy escape perspective can usefully focus attention on an important distinction between two major explanations for outbreaks: time-lagged enemy regulation and multiple equilibria.

A very common hypothesis for both insect and mammalian oscillations is that they arise from timelagged regulation of victims by their enemies. Even the simplest theoretical models of predator-prey and parasitoid-host dynamics include such lagged regulation, because enemy numerical response, in response to increasing victim density, is not instantaneous. A near-universal prediction of such models is time-lagged cycles in the population densities of enemy and victim (Blasius et al. 1999). Essentially, enemies drive victim populations to such low levels that the enemies can no longer exploit them effectively, and so in turn undergo local population declines. This allows victim populations to build up again (Royama 1992), but enemy populations lag behind. The lag in enemy response allows victim populations to increase further, faster, and this continues until eventually enemies are able to catch up (Berryman 1996; Abrams 2000). This hypothesis for population oscillations suggests that enemy-victim interactions suffice to drive persistent cycles (Berryman 1996). It does, however, require tight linkage between enemy and victim populations, either because the enemy is a specialist, or because the focal victim species, at outbreak levels, dominates the local victim assemblage.

Is it useful to think of time-lagged enemy-victim regulation as involving "enemy escape"? We are not sure. On the one hand, it is clear that victim increase happens because enemy regulation is (transiently) removed (Fig. 1, arrow 1a), just as it does (for example) during invasions with enemy release. On the other hand, in enemy-driven cycles there is no identifiable instigating "event" - or at least, the 
"event" of enemy collapse is an intrinsic part of the coupled population dynamics. Instead of saying that victims escape enemy regulation, it might be more natural to say that enemy attack provides "bounded regulation" rather than regulation to a single equilibrium density. The intrinsic nature of time-lagged regulation certainly contrasts with circumstances such as invasions, host shifts, and predator suppression that have externally imposed instigating events. It is true that intrinsic evolutionary "events" as defensive innovations and selectively driven phenological shifts can also occur without any external trigger. However, because enemy collapse in time-lagged regulation is deterministically recurrent, we suspect that many ecologists will decide that it stretches the "enemy escape" envelope too far.

A major alternative to the time-lagged regulation hypothesis is that outbreaks represent shifts between multiple equilibria, with victim populations having a low-density equilibrium under enemy regulation and a high-density equilibrium (perhaps limited by resources) which can only be attained following enemy escape. This mechanism for outbreaks fits much more comfortably with the other circumstances discussed here, because enemy escape is not intrinsic to the population dynamics but is instead triggered when ecological circumstances allow victim populations to increase beyond the capacity of enemies to control them (Royama 1992; Pureswaran et al. 2015). Most versions of the multipleequilibria hypothesis suggest that the trigger is bottom-up, with the victim population freed from enemy predator control by factors such as periods of favourable abiotic conditions, increases in food quantity or quality, or changes in landscape complexity. For example, mountain pine beetle (Dendroctonus ponderosae Hopkins) outbreaks tend to follow periods of warm, dry summers (Thomson and Shrimpton 1984). Similarly, in bark beetles, blowdown events provide large numbers of moribund trees ideal for insect attack, thus increasing populations that become outbreaks (Coulson 1979). Enemy escape is both a consequence of the initial victim population increase and a cause of further increase once enemy pressure is weakened. A second trigger is required to move the system back from the high-density to the low-density equilibrium - this time, conditions that reduce victim population densities far enough for enemies to re-establish regulation. This second trigger is often thought to be resource depletion (e.g., Aukema et al. 2008; Hall et al. 2015). As the re-establishment of regulation depends on an event external to the enemy-victim population dynamics, one could imagine escape being definitive (Fig. 1, arrow 1b), but in practice, the systems that attract researcher attention are those in which outbreaks are temporary and recurring-that is, those in which both triggers happen often enough to keep the system switching between high- and low-density states.

The attempt to fit outbreaks and oscillations into the enemy escape framework is useful in itself, because it focuses attention on the critical distinction between the time-lagged regulation and multiple-equilibria mechanisms for the outbreaks: one requires no instigating event beyond the coupled population dynamics themselves, whereas the other does. There are further implications, though, of comparing outbreaks to our other circumstances of enemy escape. For example, the potential for differing selection regimes at population peaks and troughs, with consequent eco-evolutionary dynamics, parallels the potential for evolutionary change following other kinds of enemy escape (see below). We suspect that the search for further points of commonality will be a fruitful one.

\section{Common threads and loose ends}

\section{Flavours and definitions of enemy escape}

Our review should make it apparent that enemy escape can occur in a wide variety of circumstances. Unfortunately, these circumstances have largely been considered in separate and isolated literatures. For example, the literature on enemy release during invasions has virtually no intersection with that on enemy-free space in host shifting-despite obvious analogies between escaping an enemy through introduction to a new geographical area and through colonization of a new host, and despite the fact 
that invasions by phytophagous insects and other consumers often involve host shifts in addition to geographic displacement. Although there is no doubt that research focused on each type of enemy escape will continue to be productive, we suggest that new insights can come from seeing the types of enemy escape we have considered as multiple sides of the same coin. This synthetic perspective leads us to adopt, and to propose that others adopt, a broad definition for enemy escape: any case in which a population undergoes rapid growth or attains unusual density, as a result of ecological or evolutionary changes that reduce the impact of natural enemies on victim population growth and thus disrupt previous top-down population regulation. This definition stresses change, and the change that disrupts regulation (the instigating event; Table 1) can be ecological (Fig. 1, arrow 1), evolutionary (Fig. 1, arrow 2), or involve the interaction of the two (e.g., disruption of phenological synchrony when adaptation to climate change proceeds at different rates in enemy and victim).

Focusing on change highlights two important things about enemy escape. First, there are many mechanisms (i.e., types of instigating event) that can lead to a common effect: escape from enemies. Second, enemy escape is best seen in comparisons (temporal or spatial) across the change in question; all else being equal, enemy escape occurs when the impact of natural enemies on victim populations is diminished relative to normally regulated populations. The caveat "all else being equal" is important, especially in circumstances where escape from enemies is intrinsically confounded with other changes. For example, in herbivore host shifts, enemy-free space may trade off with physiological suitability for insect development, such that enemy escape may increase herbivore population growth above what it would have been on the same host with enemies present, but not necessarily above what it was on the ancestral host. Phenological shifts and invasions (at least) are likely to bring similar complexity, as changes in enemy-victim relationships go along with changes in abiotic environments. In such cases, it may be difficult to differentiate between the effects of enemy escape and of other concurrent ecological changes, and it may even be difficult to recognize enemy escape in the first place. Even species at low densities may be escaping enemies while being kept at those low densities by climatic maladaptation or other local factors.

\section{Temporal scales of enemy escape}

Despite the basic conceptual unity of enemy escape, the hypothesized circumstances in which it occurs may see escape on different temporal scales (Table 1). There are two continua, in particular, that we suggest will be important for understanding the ecological and evolutionary ramifications of enemy escape: the speed at which escape comes about, and the duration of escape once it occurs. Because the literature on enemy escape has been fragmented and few comparisons have been drawn of escape under different circumstances, little attention has been paid to these timescales of escape. What follows, then, is necessarily speculative.

\section{How quickly do victims escape?}

The speed of the instigating events driving escape is likely to be very fast in a few cases (Table 1): essentially instantaneous for invasions, and over the course of a few generations in enemy suppression (top predator collapses under anthropogenic pressure can be precipitous, e.g., Myers and Worm 2003). Natural range expansions may take much longer, although available data are strongly biased because neoecologists generally study only those range expansions that occur quickly. Paleoecologists, in contrast, are able to detect both fast and slow expansions, and slow expansions (on ecological timescales) are common; for instance, postglacial migrations by trees in Europe and North America were typically $150-500 \mathrm{~m} /$ year (Clark et al. 1998). As the instigating event is not just the victim's range expansion but the degree to which it outpaces the enemy's, observed rates of range expansion put an upper but not a lower limit on the potential for escape. The same is true for 
phenological shifts, whether these are selective responses or byproducts of climate change. In defensive innovation, the instigating event is trait evolution itself, and here speed of escape should depend on the relative rates of trait evolution in the enemy and victim. We imagine escape happening more quickly when victims are under stronger selection than enemies (most likely with generalist enemies and attack-intolerant victims), when victims have generation times similar to or faster than those of their enemies (as for parasitoid-host systems, for instance, in contrast to insect-tree systems), and perhaps when sexual victims innovate faster than asexual enemies. We are, unfortunately, aware of no data to test these suggestions. Finally, host shifts and host-associated differentiation can happen quite rapidly, as with $R$. pomonella, which colonized apple within about 200 years of apple cultivation in North America (Walsh 1867) and became genetically differentiated on that host within at most a further 125 years (Feder 1995). Although such rapid host shifts have attracted a lot of attention, rapidity may not be the universal rule. For example, the million-year asynchrony of host shifts across gallmakers in the Solidago altissima L./gigantea Ait. system (Stireman et al. 2005) suggests that, even given suitable alternative hosts, host shifts may be quite slow either to begin or to complete.

In general, we suggest that the speed of ecological or evolutionary change will play a major role in determining whether, and how completely, a given change brings about enemy escape. Escape may be virtually ubiquitous in invasions, for example, but less common in natural range expansions because the slower expansion of the victim's distribution allows many enemies to keep pace.

\section{How long does escape last?}

The duration of escape is also likely to vary with the circumstances that brought it about. In range expansions, for example, control by natural enemies is often re-established after a handful of generations. This is "transient" escape (Fig. 1, arrow 1a). In contrast, escape after defensive innovation can sometimes last an astonishingly long time (e.g., many millions of years for plant latex and resin canals; Farrell and Mitter 1993a) despite presumed strong selection for enemy adaptations that overcome the new defense. We would consider this "definitive" escape (Fig. 1, arrow 2b), although we recognize that escape is probably never permanent and that "transient" and "definitive" are simply labels for two ends of a continuum. It seems likely that, as suggested by this particular contrast, enemy escape will be (more) transient when only ecological events are needed to end it (e.g., dispersal by enemies in range expansions) than when enemies must evolve new adaptations (e.g., behaviour, morphology, or biochemistry) to overcome victim defenses. When escape arises from enemy suppression, this idea suggests that escape should be transient if a regulating enemy is only reduced in density or locally extirpated and can re-establish, but much longer and perhaps definitive if it is globally extinct and new enemies must evolve (Solé et al. 2002). Of course, ecologists are more likely to identify enemy escape when it is more persistent, meaning that we are very likely (again) to be dealing with a biased sample of escaping enemies.

\section{Evolution after enemy escape: Evolution of increased competitive ability}

Enemy escape, no matter what its mechanism, should be accompanied by relaxed selection on defensive traits (Lahti et al. 2009). When those defensive traits are involved in trade-offs with other traits (as, from an energetic point of view, we would often expect them to be), the straightforward prediction is that enemy escape should allow novel responses to selection, freed from those trade-offs-at least if enemy escape is definitive. Surprisingly, the evolutionary consequences of this relaxed selection have been widely discussed for invasions but have received much less attention for other circumstances of enemy escape.

Invasion ecologists have paid considerable attention to the "evolution of increased competitive ability" (EICA, Blossey and Notzold 1995) hypothesis (e.g., Joshi and Vrieling 2005; Hull-Sanders et al. 
2007; Felker-Quinn et al. 2013). Interest in EICA began with the realization that the success of invasive species could reflect more than just simple ecological release from enemies. Instead, invasive species can undergo rapid evolution in response to the relaxation of enemy pressure (Müller-Schärer et al. 2004). Individuals of invasive plants are often larger and more vigorous than conspecifics in their native range or than native congenerics with which they co-occur. The EICA hypothesis explains this as the result of selection following enemy escape favouring genotypes with reduced allocation to defense and greater allocation to competitive ability.

The possibility of selection for similar reallocations away from defense has been almost completely ignored for other pathways to enemy escape, which represents both a major gap in the literature and a major opportunity for future research. There are, however, scattered exceptions. Woods et al. (2012) asked whether resource allocation in common milkweed (Asclepias syriaca) shifts away from defense after natural range expansion and at natural range edges. However, northern range-edge milkweeds (which are rarely attacked) are still heavily defended and grow relatively slowly even in common gardens. Whether milkweeds are an exception to the EICA rule or whether EICA will prove to be uncommon at range margins will remain unclear until studies of other systems are available. There have also been some studies of relaxed selection following predator removal, with findings of immediate plastic and longer term genetic declines in defensive behaviours and other traits. For example, Alaskan moose respond to vocalization playback cues from crows to avoid predation where they co-occur with large carnivores (grizzlies and wolves), but not at sites where these predators have been extinct for 50-70 years (Berger 1999). Similar effects are known in Trinidadian guppies, which have evolved differences in antipredator defenses and life history characteristics in upstream populations that lack major predators (e.g., Reznick et al. 1996; Templeton and Shriner 2004). In most studies, however, it is not clear whether reduced defense has consequences for competitive ability. Finally, EICA is also implicit in some discussions of escape following defensive innovation (e.g., Farrell and Mitter 1993b). However, this might be the case where expectations of EICA are least strong, because in many cases the victim achieves enemy escape precisely by investing resources in defense (e.g., in latex canals). Although this may then permit relaxed selection on other defensive traits, it is much less obvious that EICA should result-in contrast with invasions and enemy suppression, in which enemy escape is essentially without cost.

If escape from enemies leads to EICA or other adaptive reallocations, there is the obvious possibility of maladaptation when escape is transient. Populations that have lost defensive traits may be especially vulnerable to extirpation or even extinction when enemies are reintroduced (whether they are the original enemies or new ones) - for instance, as has occurred repeatedly after anthropogenic introductions of vertebrate predators to oceanic islands that were predator-free for a long time (Blackburn et al. 2004). Alternatively, the resumption of predator-driven selection might simply drive the reversal of reallocations or the evolution of new defenses. Which outcome is more likely will depend on the potential for rapid victim evolution (population size, life history, standing genetic variation, etc.) and on the rate at which the new enemy population builds.

\section{Evolution after enemy escape: Divergence and speciation}

Enemy escape may be implicated in evolutionary divergence, and ultimately speciation, under several scenarios. There are at least five ways that enemy escape could favour genetic divergence, and in the long term, speciation and diversification. First, reductions in mortality from enemy attack could mean larger population sizes, providing more genetic variation on which selection could act, as well as resistance to extinction in nascent lineages. Second, reduced mortality could allow victims to expand their geographic range, opening up possibilities for geographic isolation and allopatric speciation. Third, that same reduced mortality could allow populations to persist in novel habitats, with resulting disruptive selection on habitat use and traits underlying adaptation to it. Fourth, even in an unchanged 
habitat, the relaxation of selection on defense could permit, or perhaps unveil, disruptive selection on other traits (Schluter 1988; Benkman 1991). Finally, when only some populations escape enemies, the resulting heterogeneity in selection on defensive traits could drive speciation as a byproduct. However, attention paid to the idea of post-escape divergence, and to these mechanisms for it, has been extremely variable across enemy escape hypotheses.

The literature is richest with respect to ecological speciation following host shifts in herbivorous insects. Here, enemy-free space is hypothesized to play a role in permitting utilization of the new host and thus enabling disruptive selection (e.g., Feder 1995; Faucci et al. 2007; Yoder et al. 2010). Analogous disruptive selection could arise during phenological shifts if individuals developing either earlier or later escape enemies (Elzinga et al. 2007), and it is plausible that the result could be divergence into phenologically isolated morphs or even species. Interestingly, if enemy escape eases range expansions, then the same kind of disruptive selection could arise when range-margin populations freed from enemy control are able to colonize habitats differing from range-central populations. This effect would presumably complement the simpler effect of range size on speciation via likelihood of reproductive isolation.

A more macroevolutionary perspective on divergence after escape is provided by the literature on "escape and radiation" (Ehrlich and Raven 1964; Thompson 1989). Enemy escape through defensive innovation is widely supposed to be involved in the radiation of plant groups such as the furanocoumarin-containing Apiaceae (Ehrlich and Raven 1964; Cornell and Hawkins 2003) and, more broadly, various plant clades possessing latex and resin canals (Farrell et al. 1991). The precise mechanisms connecting escape to speciation and radiation are not always clear, but may involve larger population sizes and geographic ranges (e.g., Farrell et al. 1991). We might expect a similar tendency for victim radiation in other circumstances of enemy release, and in fact some studies show victim radiation after predator extinction in the fossil record (e.g., Sallan et al. 2011) or upon colonization of predatorreduced islands (Benkman 1991). However, other studies emphasize ways in which the presence of predators can drive diversification (e.g., Meyer and Kassen 2007), and this tension appears unresolved.

One obvious but poorly studied possibility is that invasions, facilitated by enemy escape, could be followed by allopatric speciation (with invading populations diverging from native-range populations and attaining species status). Although many studies have documented genetic, morphological, or behavioural differences between introduced populations and their native sources (e.g., Suarez et al. 1999; Bossdorf et al. 2005), few have considered the possibility that this might lead to speciation. One interesting exception is a study of Arctotheca populifolia (Bergius), which is invasive to Australia (from South Africa) and has diverged sufficiently in flowering phenology to have substantial reproductive isolation between invasive and native populations in a common garden (C. Brandenburger, personal communication, 2016). The speciation corollary of the enemy-release hypothesis represents a major opportunity for further research. More broadly, whether and when enemy escape favours divergence and speciation is an agenda for research that can unite both the ecological and evolutionary dimensions and the many circumstances of enemy escape.

\section{Conclusions}

We have drawn attention to commonality among a variety of ecological and evolutionary circumstances that could allow victim species to escape enemy regulation and thus increase in population density. One framework for viewing this commonality is provided in our conceptual model (Fig. 1), although we encourage ecologists to suggest other perspectives. We believe this commonality among circumstances of enemy escape is important, that attention to mechanism can let our discussion transcend idiosyncratic differences among systems, and that ecologists have missed opportunities to apply lessons from one kind of enemy escape to others. 
We hope that recognizing both the commonalities and differences among circumstances of enemy escape will let ecologists make rapid progress in understanding what happens when victims escape, whether briefly or persistently, previous regulation by their natural enemies. It remains unknown to what extent differences among circumstances of enemy escape lead to differences in the ecological and evolutionary consequences of that escape. It is precisely to encourage work along these lines that we seek here to pull disparate literatures together. The long-term consequences of enemy escape (including the evolution of increased competitive ability and divergence and radiation by escaping victims) are potentially important to the eco-evolutionary dynamics of communities and even to long-term trends in Earth's biodiversity.

\section{Acknowledgements}

We thank K.W. Dearborn for valuable input in the initial stages of this project and M.M. Giasson for editorial assistance. Jeff Clements and several anonymous reviewers made helpful comments on the manuscript. This work was supported by Discovery Grants to SBH and DSP and a Vanier Canada Graduate Scholarship to CEM from the Natural Sciences and Engineering Research Council (Canada), and by a postdoctoral fellowship to JJM from Fonds de Recherche Nature et Technologies (Quebec).

\section{Author contributions}

JJM, CEM, and SBH conceived and designed the study. JJM, CEM, SE, ALE, AH, RJ, MM, DSP, DTQ, $\mathrm{ZS}$, and SBH performed the experiments/collected the data. JJM, CEM, and SBH analyzed and interpreted the data. SBH contributed resources. JJM, CEM, SE, ALE, AH, RJ, MM, DSP, DTQ, ZS, and SBH drafted or revised the manuscript.

\section{Competing interests}

SBH is currently serving as a Subject Editor for FACETS, but was not involved in review or editorial decisions regarding this manuscript.

\section{Data accessibility statement}

All relevant data are within the paper.

\section{References}

Abeli T, Gentili R, Mondoni A, Orsenigo S, and Rossi G. 2014. Effects of marginality on plant population performance. Journal of Biogeography, 41(2): 239-249. DOI: 10.1111/jbi.12215

Abrams PA. 2000. The evolution of predator-prey interactions: theory and evidence. Annual Review of Ecology and Systematics, 31: 79-105. DOI: 10.1146/annurev.ecolsys.31.1.79

Aliabadi BW, and Juliano SA. 2002. Escape from gregarine parasites affects the competitive interactions of an invasive mosquito. Biological Invasions, 4(3): 283-297. PMID: 19777120 DOI: 10.1023/A:1020933705556

Alizon S, Hurford A, Mideo N, and van Baalen M. 2009. Virulence evolution and the trade-off hypothesis: history, current state of affairs and the future. Journal of Evolutionary Biology, 22(2): 245-259. PMID: 19196383 DOI: 10.111/j.1420-9101.2008.01658.x

Ancheta J, and Heard SB. 2011. Impacts of insect herbivores on rare plant populations. Biological Conservation, 144(10): 2395-2402. DOI: 10.1016/j.biocon.2011.06.019 
Andersson M, and Waldeck P. 2006. Reproductive tactics under severe egg predation: an eider's dilemma. Oecologia, 148(2): 350-355. PMID: 16468054 DOI: 10.1007/s00442-006-0374-7

Andrewartha HG, and Birch LC. 1954. The distribution and abundance of animals. University of Chicago Press, Chicago, Illinois.

Aukema BH, Carroll AL, Zheng Y, Zhu J, Raffa KF, Moore RD, et al. 2008. Movement of outbreak populations of mountain pine beetle: influences of spatiotemporal patterns and climate. Ecography, 31(3): 348-358. DOI: 10.1111/j.0906-7590.2007.05453.x

Ballabeni P, Wlodarczyk M, and Rahier M. 2001. Does enemy-free space for eggs contribute to a leaf beetle's oviposition preference for a nutritionally inferior host plant? Functional Ecology, 15(3): 318-324. DOI: 10.1046/j.1365-2435.2001.00529.x

Barnosky AD, Matzke N, Tomiya S, Wogan GOU, Swartz B, Quental TB, et al. 2011. Has the Earth's sixth mass extinction already arrived? Nature, 471(7336): 51-57. PMID: 21368823 DOI: 10.1038/ nature09678

Beal BF, Parker MR, and Vencile KW. 2001. Seasonal effects of intraspecific density and predator exclusion along a shore-level gradient on survival and growth of juveniles of the soft-shell clam, Mya arenaria L., in Maine, USA. Journal of Experimental Marine Biology and Ecology, 264: 133-169. DOI: 10.1016/S0022-0981(01)00320-3

Becerra JX. 2003. Synchronous coadaptation in an ancient case of herbivory. Proceedings of the National Academy of Sciences of the United States of America, 100(22): 12804-12807. PMID: 14555762 DOI: $10.1073 /$ pnas. 2133013100

Benkman CW. 1991. Predation, seed size partitioning and the evolution of body size in seed-eating finches. Evolutionary Ecology, 5(2): 118-127. DOI: 10.1007/BF02270828

Berdegue M, Trumble JT, Hare JD, and Redak RA. 1996. Is it enemy-free space? The evidence for terrestrial insects and freshwater arthropods. Ecological Entomology, 21(3): 203-217. DOI: 10.1111/ j.1365-2311.1996.tb01237.x

Berenbaum M. 1983. Coumarins and caterpillars: a case for coevolution. Evolution, 37(1): 163-179. PMID: 28568024 DOI: 10.1111/j.1558-5646.1983.tb05524.x

Berger J. 1999. Anthropogenic extinction of top carnivores and interspecific animal behaviour: implications of the rapid decoupling of a web involving wolves, bears, moose and ravens. Proceedings of the Royal Society B: Biological Sciences, 266(1435): 2261-2267. DOI: 10.1098/rspb.1999.0917

Berger KM, and Conner MM. 2008. Recolonizing wolves and mesopredator suppression of coyotes: impacts on pronghorn population dynamics. Ecological Applications, 18(3): 599-612. PMID: 18488620 DOI: $10.1890 / 07-0308.1$

Berlocher SH, and Feder JL. 2002. Sympatric speciation in phytophagous insects: moving beyond controversy? Annual Review of Entomology, 47(1): 773-815. DOI: 10.1146/annurev. ento.47.091201.145312

Berryman AA. 1996. What causes population cycles of forest Lepidoptera? Trends in Ecology \& Evolution, 11(1): 28-32. PMID: 21237756 DOI: 10.1016/0169-5347(96)81066-4 
Bewick S, Cantrell RS, Cosner C, and Fagan WF. 2016. How resource phenology affects consumer population dynamics. The American Naturalist, 187(2): 151-166. PMID: 26807744 DOI: $10.1086 /$ 684432

Blackburn TM, Cassey P, Duncan RP, Evans KL, and Gaston KJ. 2004. Avian extinction and mammalian introductions on oceanic islands. Science, 305(5692): 1955-1958. PMID: 15448269 DOI: $10.1126 /$ science.1101617

Blasius B, Huppert A, and Stone L. 1999. Complex dynamics and phase synchronization in spatially extended ecological systems. Nature, 399(6734): 354-359. PMID: 10360572 DOI: 10.1038/20676

Blossey B, and Notzold R. 1995. Evolution of increased competitive ability in invasive nonindigenous plants: a hypothesis. Journal of Ecology, 83(5): 887-889. DOI: 10.2307/2261425

Borer ET, Halpern BS, and Seabloom EW. 2006. Asymmetry in community regulation: effects of predators and productivity. Ecology, 87(11): 2813-2820. PMID: 17168025 DOI: 10.1890/0012-9658 (2006)87[2813:AICREO]2.0.CO;2

Bossdorf O, Auge H, Lafuma L, Rogers WE, Siemann E, and Prati D. 2005. Phenotypic and genetic differentiation between native and introduced plant populations. Oecologia, 144(1): 1-11. PMID: 15891837 DOI: $10.1007 /$ s00442-005-0070-Z

Both C, van Asch M, Bijlsma RG, van den Burg AB, and Visser ME. 2009. Climate change and unequal phenological changes across four trophic levels: constraints or adaptations? Journal of Animal Ecology, 78(1): 73-83. PMID: 18771506 DOI: 10.1111/j.1365-2656.2008.01458.x

Braje TJ, and Erlandson JM. 2013. Human acceleration of animal and plant extinctions: a Late Pleistocene, Holocene, and Anthropocene continuum. Anthropocene, 4: 14-23. DOI: 10.1016/j. ancene.2013.08.003

Brett MT, and Goldman CR. 1997. Consumer versus resource control in freshwater pelagic food webs. Science, 275(5298): 384-386. PMID: 8994034 DOI: 10.1126/science.275.5298.384

Brown JH. 1984. On the relationship between abundance and distribution of species. The American Naturalist, 124(2): 255-279. DOI: 10.1086/284267

Buse A, Dury SJ, Woodburn RJW, Perrins CM, and Good JEG. 1999. Effects of elevated temperature on multi-species interactions: the case of Pedunculate Oak, Winter Moth and Tits. Functional Ecology, 13(Suppl. 1): 74-82. DOI: 10.1046/j.1365-2435.1999.00010.x

Cahill AE, Aiello-Lammens ME, Fisher-Reid MC, Hua X, Karanewsky CJ, Ryu HY, et al. 2012. How does climate change cause extinction? Proceedings of the Royal Society B: Biological Sciences, 280(1750): 20121890. PMID: 23075836 DOI: 10.1098/rspb.2012.1890

Carpenter SR, Kitchell JF, Hodgson JR, Cochran PA, Elser JJ, Elser MM, et al. 1987. Regulation of lake primary productivity by food web structure. Ecology, 68(6): 1863-1876. DOI: 10.2307/1939878

Carroll L. 1871. Through the looking-glass. Macmillan, London, UK.

Chuine I. 2010. Why does phenology drive species distribution? Philosophical Transactions of the Royal Society B: Biological Sciences, 365(1555): 3149-3160. PMID: 20819809 DOI: $10.1098 /$ rstb.2010.0142 
Clark JS, Fastie C, Hurtt G, Jackson ST, Johnson C, King GA, et al. 1998. Reid's Paradox of Rapid Plant Migration: dispersal theory and interpretation of paleoecological records. BioScience, 48(1): 13-24. DOI: $10.2307 / 1313224$

Clemente S, Hernández JC, Rodríguez A, and Brito A. 2010. Identifying keystone predators and the importance of preserving functional diversity in sublittoral rocky-bottom areas. Marine Ecology Progress Series, 413(5): 55-67. DOI: 10.3354/meps08700

Colautti RI, Ricciardi A, Grigorovich IA, and MacIsaac HJ. 2004. Is invasion success explained by the enemy release hypothesis? Ecology Letters, 7(8): 721-733. DOI: 10.1111/j.1461-0248.2004.00616.x

Coon CAC, and Martin LB. 2014. Patterns of haemosporidian prevalence along a range expansion in introduced Kenyan house sparrows Passer domesticus. Journal of Avian Biology, 45(1): 34-42. DOI: 10.1111/j.1600-048X.2013.00235.X

Cornell HV, and Hawkins BA. 2003. Herbivore responses to plant secondary compounds: a test of phytochemical coevolution theory. The American Naturalist, 161(4): 507-522. PMID: 12776881 DOI: $10.1086 / 368346$

Coulson RN. 1979. Population dynamics of bark beetles. Annual Review of Entomology, 24(1): 417-447. DOI: 10.1146/annurev.en.24.010179.002221

Crooks KR, and Soulé ME. 1999. Mesopredator release and avifaunal extinctions in a fragmented system. Nature, 400(6744): 563-566. DOI: 10.1038/23028

Davenport JM, and Chalcraft DR. 2013. Nonconsumptive effects in a multiple predator system reduce the foraging efficiency of a keystone predator. Ecology and Evolution, 3(9): 3063-3072. PMID: 24101994 DOI: 10.1002/ece3.691

Dawkins R, and Krebs JR. 1979. Arms races between and within species. Proceedings of the Royal Society B: Biological Sciences, 205(1161): 489-511. PMID: 42057 DOI: 10.1098/rspb.1979.0081

Denno RF, Larsson S, and Olmstead KL. 1990. Role of enemy-free space and plant quality in hostplant selection by willow beetles. Ecology, 71(1): 124-137. DOI: 10.2307/1940253

Drummond AJ, Rambaut A, Shapiro B, and Pybus OG. 2005. Bayesian coalescent inference of past population dynamics from molecular sequences. Molecular Biology and Evolution, 22(5): 1185-1192. PMID: 15703244 DOI: 10.1093/molbev/msi103

Dussourd DE. 2009. Do canal-cutting behaviours facilitate host-range expansion by insect herbivores? Biological Journal of the Linnean Society, 96(4): 715-731. DOI: 10.1111/j.1095-8312.2008.01168.x

Dussourd DE, and Denno RF. 1991. Deactivation of plant defense: correspondence between insect behavior and secretory canal architecture. Ecology, 72(4): 1383-1396. DOI: 10.2307/1941110

Edger PP, Heidel-Fischer HM, Bekaert M, Rota J, Glöckner G, Platts AE, et al. 2015. The butterfly plant arms-race escalated by gene and genome duplications. Proceedings of the National Academy of Sciences of the United States of America, 112(27): 8362-8366. DOI: 10.1073/pnas.1503926112

Ehrlich PR, and Raven PH. 1964. Butterflies and plants: a study in coevolution. Evolution, 18(4): 586-608. DOI: 10.1111/j.1558-5646.1964.tb01674.x 
Ellis JC, Shulman MJ, Wood M, Witman JD, and Lozyniak S. 2007. Regulation of intertidal food webs by avian predators on New England rocky shores. Ecology, 88(4): 853-863. PMID: 17536702 DOI: $10.1890 / 06-0593$

Elzinga JA, Atlan A, Biere A, Gigord L, Weis AE, and Bernasconi G. 2007. Time after time: flowering phenology and biotic interactions. Trends in Ecology \& Evolution, 22(8): 432-439. PMID: 17573151 DOI: $10.1016 /$ j.tree.2007.05.006

Estes JA, Terborgh J, Brashares JS, Power ME, Berger J, Bond WJ, et al. 2011. Trophic downgrading of planet Earth. Science, 333(6040): 301-306. PMID: 21764740 DOI: 10.1126/science.1205106

Ewald PW. 1994. Evolution of infectious disease. Oxford University Press, New York, New York.

Farrell BD, and Mitter C. 1993a. Phylogenetic determinants of insect/plant community diversity. In Species diversity in ecological communities. Edited by RE Ricklefs and D Schluter. University of Chicago Press, Chicago, Illinois. pp. 253-266.

Farrell BD, and Mitter C. 1993b. Species diversity: regional and historical influences. In Species diversity in ecological communities. Edited by RE Ricklefs and D Schluter. University of Chicago Press, Chicago, Illinois. pp. 350-363.

Farrell BD, Dussourd DE, and Mitter C. 1991. Escalation of plant defense: do latex and resin canals spur plant diversification? The American Naturalist, 138(4): 881-900. DOI: 10.1086/285258

Faucci A, Toonen RJ, and Hadfield MG. 2007. Host shift and speciation in a coral-feeding nudibranch. Proceedings of the Royal Society B: Biological Sciences, 274(1606): 111-119. PMID: 17134995 DOI: $10.1098 / \mathrm{rspb} .2006 .3685$

Feder JL. 1995. The effects of parasitoids on sympatric host races of Rhagoletis pomonella (Diptera: Tephritidae). Ecology, 76(3): 801-813. DOI: 10.2307/1939346

Felker-Quinn E, Schweitzer JA, and Bailey JK. 2013. Meta-analysis reveals evolution in invasive plant species but little support for Evolution of Increased Competitive Ability (EICA). Ecology and Evolution, 3(3): 739-751. PMID: 23531703 DOI: 10.1002/ece3.488

Forrest J, and Miller-Rushing AJ. 2010. Toward a synthetic understanding of the role of phenology in ecology and evolution. Philosophical Transactions of the Royal Society B: Biological Sciences, 365(1555): 3101-3112. PMID: 20819806 DOI: 10.1098/rstb.2010.0145

Freed TZ, Kesavaraju B, and Leisnham PT. 2014. Effects of competition and predation by native mosquitoes on the North American invasion of Aedes japonicus japonicus (Diptera: Culicidae). Journal of Medical Entomology, 51(6): 1159-1167. PMID: 26309302 DOI: 10.1603/ME13179

Freeman RS, Brody AK, and Neefus CD. 2003. Flowering phenology and compensation for herbivory in Ipomopsis aggregata. Oecologia, 136(3): 394-401. PMID: 12783294 DOI: $10.1007 /$ s00442-003-1276-6

Frid CLJ, and James R. 1988. The role of epibenthic predators in structuring the marine invertebrate community of a British coastal salt marsh. Netherlands Journal of Sea Research, 22: 307-314. DOI: 10.1016/0077-7579(88)90033-6 
Fung T, Farnsworth KD, Reid DG, and Rossberg AG. 2015. Impact of biodiversity loss on production in complex marine food webs mitigated by prey-release. Nature Communications, 6: 6657. PMID: 25799523 DOI: 10.1038/ncomms7657

Futuyma DJ, and Agrawal AA. 2009. Macroevolution and the biological diversity of plants and herbivores. Proceedings of the National Academy of Sciences of the United States of America, 106(43): 18054-18061. PMID: 19815508 DOI: 10.1073/pnas.0904106106

Garcia D, Zamora R, Gómez JM, Jordano P, and Hódar JA. 2000. Geographical variation in seed production, predation and abortion in Juniperus communis throughout its range in Europe. Journal of Ecology, 88(3): 435-446. DOI: 10.1046/j.1365-2745.2000.00459.x

Gaston KJ. 2009. Geographic range limits of species. Proceedings of the Royal Society B: Biological Sciences, 276(1661): 1391-1393. PMID: 19324808 DOI: 10.1098/rspb.2009.0100

Gillett JB. 1962. Pest pressure, an underestimated factor in evolution. Systematics Association Publication, 4: 37-46.

Ginzburg LR, and Krebs CJ. 2015. Mammalian cycles: internally defined periods and interactiondriven amplitudes. PeerJ, 3: e1180. PMID: 26339557 DOI: 10.7717/peerj.1180

Gravel D, Massol F, Canard E, Mouillot D, and Mouquet N. 2011. Trophic theory of island biogeography. Ecology Letters, 14(10): 1010-1016. PMID: 21806744 DOI: 10.1111/j.1461-0248.2011.01667.x

Hairston NG, Smith FE, and Slobodkin LB. 1960. Community structure, population control, and competition. The American Naturalist, 94(879): 421-425. DOI: 10.1086/282146

Hall AA, Gherlenda AN, Hasegawa S, Johnson SN, Cook JM, and Riegler M. 2015. Anatomy of an outbreak: the biology and population dynamics of a Cardiaspina psyllid species in an endangered woodland ecosystem. Agricultural and Forest Entomology, 17(3): 292-301. DOI: 10.1111/afe.12106

Heard SB, and Hauser DL. 1995. Key evolutionary innovations and their ecological mechanisms. Historical Biology, 10(2): 151-173. DOI: 10.1080/10292389509380518

Heard SB, Stireman JO III, Nason JD, Cox GH, Kolacz CR, and Brown JM. 2006. On the elusiveness of enemy-free space: spatial, temporal, and host-plant-related variation in parasitoid attack rates on three gallmakers of goldenrods. Oecologia, 150(3): 421-434. PMID: 16944244 DOI: $10.1007 /$ s00442-006-0529-6

Herms DA, and Mattson WJ. 1992. The dilemma of plants: to grow or defend. The Quarterly Review of Biology, 67(3): 283-335. DOI: 10.1086/417659

Holt RD, and Lawton JH. 1994. The ecological consequences of shared natural enemies. Annual Review of Ecology and Systematics, 25: 495-520. DOI: 10.1146/annurev.es.25.110194.002431

Holt RD, Gomulkiewicz R, and Barfield M. 2003. The phenomenology of niche evolution via quantitative traits in a 'black-hole'sink. Proceedings of the Royal Society B: Biological Sciences, 270(1511): 215-224. PMID: 12590763 DOI: 10.1098/rspb.2002.2219

Hrbacek J, Dvorakova M, Korinek V, and Prochazkova L. 1961. Demonstration of the effect of the fish stock on the species composition of zooplankton and the intensity of metabolism of the whole plankton association. Internationale Vereinigung für Theoretische und Angewandte Limnologie: Verhandlungen, 14: 192-195. 
Hull-Sanders HM, Clare R, Johnson RH, and Meyer GA. 2007. Evaluation of the evolution of increased competitive ability (EICA) hypothesis: loss of defense against generalist but not specialist herbivores. Journal of Chemical Ecology, 33(4): 781-799. PMID: 17333377 DOI: 10.1007/ s10886-007-9252-y

Hunter AF, and Elkinton JS. 2000. Effects of synchrony with host plant on populations of a springfeeding Lepidopteran. Ecology, 81(5): 1248-1261. DOI: 10.1890/0012-9658(2000)081[1248: EOSWHP]2.0.CO;2

Janz N. 2011. Ehrlich and Raven revisited: mechanisms underlying codiversification of plants and enemies. Annual Review of Ecology, Evolution, and Systematics, 42(1): 71-89. DOI: $10.1146 /$ annurev-ecolsys-102710-145024

Jeffries MJ, and Lawton JH. 1984. Enemy free space and the structure of ecological communities. Biological Journal of the Linnean Society, 23(4): 269-286. DOI: 10.1111/j.1095-8312.1984.tb00145.x

Jeppesen E, Madsen EA, Jensen JP, and Anderson N. 1996. Reconstructing the past density of planktivorous fish and trophic structure from sedimentary zooplankton fossils: a surface sediment calibration data set from shallow lakes. Freshwater Biology, 36(1): 115-127. DOI: 10.1046/ j.1365-2427.1996.00085.x

Jongejans E, Sheppard AW, and Shea K. 2006. What controls the population dynamics of the invasive thistle Carduus nutans in its native range? Journal of Applied Ecology, 43(5): 877-886. DOI: 10.1111/ j.1365-2664.2006.01228.x

Joshi J, and Vrieling K. 2005. The enemy release and EICA hypothesis revisited: incorporating the fundamental difference between specialist and generalist herbivores. Ecology Letters, 8(7): 704-714. DOI: $10.1111 / j .1461-0248.2005 .00769 . x$

Karban R. 2007. Deciduous leaf drop reduces insect herbivory. Oecologia, 153(1): 81-88. PMID: 17375327 DOI: $10.1007 /$ s00442-007-0709-Z

Keane RM, and Crawley MJ. 2002. Exotic plant invasions and the enemy release hypothesis. Trends in Ecology \& Evolution, 17(4): 164-170. DOI: 10.1016/S0169-5347(02)02499-0

Kelley P, Kowalewski M, and Hansen TA. 2003. Predator-prey interactions in the fossil record. Kluwer Academic/Plenum Publishers, New York, New York.

Kirkpatrick M, and Barton NH. 1997. Evolution of a species' range. The American Naturalist, 150(1): 1-23. PMID: 18811273 DOI: $10.1086 / 286054$

Lack D. 1954. The natural regulation of animal numbers. Clarendon Press, Oxford, UK.

Lahti DC, Johnson NA, Ajie BC, Otto SP, Hendry AP, Blumstein DT, et al. 2009. Relaxed selection in the wild. Trends in Ecology \& Evolution, 24(9): 487-496. PMID: 19500875 DOI: 10.1016/j. tree.2009.03.010

Lakeman-Fraser P, and Ewers RM. 2013. Enemy release promotes range expansion in a host plant. Oecologia, 172(4): 1203-1212. PMID: 23239216 DOI: 10.1007/s00442-012-2555-X

Leppänen SA, Altenhofer E, Liston AD, and Nyman T. 2012. Phylogenetics and evolution of hostplant use in leaf-mining sawflies (Hymenoptera: Tenthredinidae: Heterarthrinae). Molecular Phylogenetics and Evolution, 64(2): 331-341. PMID: 22531610 DOI: 10.1016/j.ympev.2012.04.005 
Leppänen SA, Altenhofer E, Liston AD, and Nyman T. 2013. Ecological versus phylogenetic determinants of trophic associations in a plant-leafminer-parasitoid food web. Evolution, 67(5): 1493-1502. PMID: 23617924 DOI: 10.1111/evo.12028

Lichter-Marck IH, Wylde M, Aaron E, Oliver JC, and Singer MS. 2015. The struggle for safety: effectiveness of caterpillar defenses against bird predation. Oikos, 124(4): 525-533. DOI: 10.1111/ oik.01515

Liu H, and Stiling P. 2006. Testing the enemy release hypothesis: a review and meta-analysis. Biological Invasions, 8(7): 1535-1545. DOI: 10.1007/s10530-005-5845-y

Lloyd N, Wilson JM, and Barclay RM. 2006. Behaviors of western spruce budworm moths (Choristoneura occidentalis) as defences against bat predation. Journal of Insect Behavior, 19(4): 533-544. DOI: 10.1007/s10905-006-9042-3

Lowry E, Rollinson EJ, Laybourn AJ, Scott TE, Aiello-Lammens ME, Gray SM, et al. 2013. Biological invasions: a field synopsis, systematic review, and database of the literature. Ecology and Evolution, 3(1): 182-196. PMID: 23404636 DOI: $10.1002 /$ ece3.431

Magurran AE. 1990. The adaptive significance of schooling as an anti-predator defence in fish. Annales Zoologici Fennici, 27(2): 51-66.

Maron JL, and Crone E. 2006. Herbivory: effects on plant abundance, distribution and population growth. Proceedings of the Royal Society B: Biological Sciences, 273(1601): 2575-2584. PMID: 17002942 DOI: $10.1098 / \mathrm{rspb} .2006 .3587$

Maron JL, and Vilà M. 2001. When do herbivores affect plant invasion? Evidence for the natural enemies and biotic resistance hypotheses. Oikos, 95(3): 361-373. DOI: 10.1034/j.1600-0706. 2001.950301.x

Meijer K, Schilthuizen M, Beukeboom L, and Smit C. 2016. A review and meta-analysis of the enemy release hypothesis in plant-herbivorous insect systems. PeerJ, 4: e2778. PMID: 28028463 DOI: $10.7717 /$ peerj. 2778

Meyer JR, and Kassen R. 2007. The effects of competition and predation on diversification in a model adaptive radiation. Nature, 446(7134): 432-435. PMID: 17377581 DOI: 10.1038/nature05599

Miyatake T, Katayama K, Takeda Y, Nakashima A, Sugita A, and Mizumoto M. 2004. Is deathfeigning adaptive? Heritable variation in fitness difference of death-feigning behaviour. Proceedings of the Royal Society B: Biological Sciences, 271: 2293-2296. PMID: 15539355 DOI: 10.1098/ rspb.2004.2858

Morriën E, Engelkes T, Macel M, Meisner A, and van der Putten WH. 2010. Climate change and invasion by intracontinental range-expanding exotic plants: the role of biotic interactions. Annals of Botany, 105: 843-848. PMID: 20354072 DOI: 10.1093/aob/mcq064

Müller-Schärer H, Schaffner U, and Steinger T. 2004. Evolution in invasive plants: implications for biological control. Trends in Ecology \& Evolution, 19(8): 417-422. PMID: 16701299 DOI: 10.1016/j. tree.2004.05.010

Murdoch WW. 1994. Population regulation in theory and practice. Ecology, 75(2): 271-287. DOI: $10.2307 / 1939533$ 
Murphy SM, Lill JT, Bowers MD, and Singer MS. 2014. Enemy-free space for parasitoids. Environmental Entomology, 43(6): 1465-1474. PMID: 25479197 DOI: 10.1603/EN13201

Murray BG Jr. 1999. Can the population regulation controversy be buried and forgotten? Oikos, 84(1): 148-152. DOI: $10.2307 / 3546875$

Myers RA, and Worm B. 2003. Rapid worldwide depletion of predatory fish communities. Nature, 423(6937): 280-283. PMID: 12748640 DOI: 10.1038/nature01610

Myers RA, Baum JK, Shepherd TD, Powers SP, and Peterson CH. 2007. Cascading effects of the loss of apex predatory sharks from a coastal ocean. Science, 315(5820): 1846-1850. PMID: 17395829 DOI: 10.1126/science.1138657

Paine RT. 1969. The Pisaster-Tegula interaction: prey patches, predator food preference, and intertidal community structure. Ecology, 50(6): 950-961. DOI: 10.2307/1936888

Pauly D, Christensen V, Dalsgaard J, Froese R, and Torres F Jr. 1998. Fishing down marine food webs. Science, 279(5352): 860-863. PMID: 9452385 DOI: 10.1126/science.279.5352.860

Phillips BL, Kelehear C, Pizzatto L, Brown GP, Barton D, and Shine R. 2010. Parasites and pathogens lag behind their host during periods of host range advance. Ecology, 91(3): 872-881. PMID: 20426344 DOI: $10.1890 / 09-0530.1$

Prange S, and Gehrt SD. 2007. Response of skunks to a simulated increase in coyote activity. Journal of Mammalogy, 88(4): 1040-1049. DOI: 10.1644/06-MAMM-A-236R1.1

Prugh LR, Stoner CJ, Epps CW, Bean WT, Ripple WJ, Laliberte AS, et al. 2009. The rise of the mesopredator. BioScience, 59(9): 779-791. DOI: 10.1525/bio.2009.59.9.9

Pureswaran DS, De Grandpré L, Paré D, Taylor A, Barrette M, Morin H, et al. 2015. Climate-induced changes in host tree-insect phenology may drive ecological state-shift in boreal forests. Ecology, 96(6): 1480-1491. DOI: 10.1890/13-2366.1

Pureswaran DS, Johns R, Heard SB, and Quiring D. 2016. Paradigms in eastern spruce budworm (Lepidoptera: Tortricidae) population ecology: a century of debate. Environmental Entomology, 45(6): 1333-1342. PMID: 28028079 DOI: 10.1093/ee/nvw103

Reznick DN, Butler MJ IV, Rodd FH, and Ross P. 1996. Life-history evolution in guppies (Poecilia reticulata) 6. Differential mortality as a mechanism for natural selection. Evolution, 50(4): 1651-1660. PMID: 28565709 DOI: 10.1111/j.1558-5646.1996.tb03937.x

Ritchie EG, and Johnson CN. 2009. Predator interactions, mesopredator release and biodiversity conservation. Ecology Letters, 12(9): 982-998. PMID: 19614756 DOI: 10.1111/j.1461-0248.2009.01347.x

Roemer GW, Gompper ME, and van Valkengurgh B. 2009. The ecological role of the mammalian mesocarnivore. BioScience, 59(2): 165-173. DOI: 10.1525/bio.2009.59.2.9

Rogers CM, and Heard SB. 2000. The mesopredator release hypothesis: integrating landbird management with ecological theory. Studies in Avian Biology, 21: 138-143.

Rosenheim JA. 1998. Higher-order predators and the regulation of insect herbivore populations. Annual Review of Entomology, 43(1): 421-447. PMID: 9444753 DOI: 10.1146/annurev.ento.43.1.421

Royama T. 1992. Analytical population dynamics. Chapman and Hall, New York, New York. 
Russell EP. 1989. Enemies hypothesis: a review of the effect of vegetational diversity on predatory insects and parasitoids. Environmental Entomology, 18(4): 590-599. DOI: 10.1093/ee/18.4.590

Russell FL, and Louda SM. 2004. Phenological synchrony affects interaction strength of an exotic weevil with Platte thistle, a native host plant. Oecologia, 139(4): 525-534. PMID: 15057555 DOI: 10.1007/ s00442-004-1543-1

Sallan LC, Kammer TW, Ausich WI, and Cook LA. 2011. Persistent predator-prey dynamics revealed by mass extinction. Proceedings of the National Academy of Sciences of the United States of America, 108(20): 8335-8338. PMID: 21536875 DOI: 10.1073/pnas.1100631108

Santos HM, Paiva MR, Rocha S, Kerdelhué C, and Branco M. 2013. Phenotypic divergence in reproductive traits of a moth population experiencing a phenological shift. Ecology and Evolution, 3(15): 5098-5108. PMID: 24455139 DOI: 10.1002/ece3.865

Schluter D. 1988. Character displacement and the adaptive divergence of finches on islands and continents. The American Naturalist, 131(6): 799-824. DOI: 10.1086/284823

Sexton JP, McIntyre PJ, Angert AL, and Rice KJ. 2009. Evolution and ecology of species range limits. Annual Review of Ecology, Evolution, and Systematics, 40: 415-436. DOI: 10.1146/annurev. ecolsys.110308.120317

Singer MC, and Parmesan C. 2010. Phenological asynchrony between herbivorous insects and their hosts: signal of climate change or pre-existing adaptive strategy? Philosophical Transactions of the Royal Society B: Biological Sciences, 365(1555): 3161-3176. PMID: 20819810 DOI: 10.1098/ rstb.2010.0144

Singer MS, and Stireman JO III. 2005. The tri-trophic niche concept and adaptive radiation of phytophagous insects. Ecology Letters, 8(12): 1247-1255. DOI: 10.1111/j.1461-0248.2005.00835.x

Solé RV, Montoya JM, and Erwin DH. 2002. Recovery after mass extinction: evolutionary assembly in large-scale biosphere dynamics. Philosophical Transactions of the Royal Society B: Biological Sciences, 357(1421): 697-707. PMID: 12079530 DOI: 10.1098/rstb.2001.0987

Soulé ME, Bolger DT, Alberts AC, Wrights J, Sorice M, and Hill S. 1988. Reconstructed dynamics of rapid extinctions of chaparral-requiring birds in urban habitat islands. Conservation Biology, 2(1): 75-92. DOI: 10.1111/j.1523-1739.1988.tb00337.x

Stireman JO III, Nason JD, and Heard SB. 2005. Host-associated genetic differentiation in phytophagous insects: general phenomenon or isolated exceptions? Evidence from a goldenrod-insect community. Evolution, 59(12): 2573-2587. PMID: 16526505 DOI: 10.1554/05-222.1

Suarez AV, Tsutsui ND, Holway DA, and Case TJ. 1999. Behavioral and genetic differentiation between native and introduced populations of the Argentine ant. Biological Invasions, 1(1): 43-53. DOI: 10.1023/A:1010038413690

Svenning JC, Gravel D, Holt RD, Schurr FM, Thuiller W, Münkemüller T, et al. 2014. The influence of interspecific interactions on species range expansion rates. Ecography, 37(12): 1198-1209. PMID: 25722537 DOI: 10.1111/j.1600-0587.2013.00574.x

Templeton CN, and Shriner WM. 2004. Multiple selection pressures influence Trinidadian guppy (Poecilia reticulata) antipredator behavior. Behavioral Ecology, 15(4): 673-678. DOI: 10.1093/ beheco/arh065 
Thompson JN. 1989. Concepts of coevolution. Trends in Ecology \& Evolution, 4(6): 179-183. PMID: 21227347 DOI: 10.1016/0169-5347(89)90125-0

Thompson JN. 1994. The coevolutionary process. University of Chicago Press, Chicago, Illinois.

Thomson AJ, and Shrimpton DM. 1984. Weather associated with the start of mountain pine beetle outbreaks. Canadian Journal of Forest Research, 14(2): 255-258. DOI: 10.1139/x84-049

Tikkanen OP, and Julkunen-Tiitto R. 2003. Phenological variation as protection against defoliating insects: the case of Quercus robur and Operophtera brumata. Oecologia, 136(2): 244-251. PMID: 12728310 DOI: $10.1007 /$ s00442-003-1267-7

Torchin ME, Lafferty KD, and Kuris AM. 2002. Parasites and marine invasions. Parasitology, 124(7): 137-151. PMID: 12396221 DOI: 10.1017/S0031182002001506

Torchin ME, Lafferty KD, Dobson AP, McKenzie VJ, and Kuris AM. 2003. Introduced species and their missing parasites. Nature, 421(6923): 628-630. PMID: 12571595 DOI: 10.1038/nature01346

van Asch M, and Visser ME. 2007. Phenology of forest caterpillars and their host trees: the importance of synchrony. Annual Review of Entomology, 52: 37-55. PMID: 16842033 DOI: $10.1146 /$ annurev.ento.52.110405.091418

van Grunsven RHA, van der Putten WH, Bezemer TM, Berendse F, and Veenendaal EM. 2010. Plantsoil interactions in the expansion and native range of a poleward shifting plant species. Global Change Biology, 16(1): 380-385. DOI: 10.1111/j.1365-2486.2009.01996.x

van Valen L. 1973. A new evolutionary law. Evolutionary Theory, 1: 1-30.

Vance-Chalcraft HD, Rosenheim JA, Vonesh JR, Osenberg CW, and Sih A. 2007. The influence of intraguild predation on prey suppression and prey release: a meta-analysis. Ecology, 88(11): 26892696. PMID: 18051635 DOI: $10.1890 / 06-1869.1$

Vermeij GJ. 1987. Evolution and escalation: an ecological history of life. Princeton University Press, Princeton, New Jersey.

Visser ME, and Both C. 2005. Shifts in phenology due to global climate change: the need for a yardstick. Proceedings of the Royal Society B: Biological Sciences, 272(1581): 2561-2569. PMID: 16321776 DOI: $10.1098 / \mathrm{rspb} .2005 .3356$

Visser ME, Caro SP, van Oers K, Schaper SV, and Helm B. 2010. Phenology, seasonal timing and circannual rhythms: towards a unified framework. Philosophical Transactions of the Royal Society B: Biological Sciences, 365(1555): 3113-3127. PMID: 20819807 DOI: 10.1098/rstb.2010.0111

Wake DB, and Vredenburg VT. 2008. Are we in the midst of the sixth mass extinction? A view from the world of amphibians. Proceedings of the National Academy of Sciences of the United States of America, 105: 11466-11473. PMID: 18695221 DOI: 10.1073/pnas.0801921105

Walsh BD. 1867. The apple-worm and the apple maggot. Journal of Horticulture, 2: 338-343.

Weber MG, and Agrawal AA. 2014. Defense mutualisms enhance plant diversification. Proceedings of the National Academy of Sciences of the United States of America, 111(46): 16442-16447. PMID: 25349406 DOI: $10.1073 /$ pnas. 1413253111 
Woiwod IP, and Hanski I. 1992. Patterns of density dependence in moths and aphids. Journal of Animal Ecology, 61(3): 619-629. DOI: 10.2307/5617

Woods EC, Hastings AP, Turley NE, Heard SB, and Agrawal AA. 2012. Adaptive geographical clines in the growth and defense of a native plant. Ecological Monographs, 82(2): 149-168. DOI: 10.1890/ 11-1446.1

Wroe S, Field J, Fullagar R, and Jermin LS. 2004. Megafaunal extinction in the late Quaternary and the global overkill hypothesis. Alcheringa: An Australasian Journal of Palaeontology, 28(1): 291-331. DOI: $10.1080 / 03115510408619286$

Yoder JB, Clancey E, Des Roches S, Eastman JM, Gentry L, Godsoe W, et al. 2010. Ecological opportunity and the origin of adaptive radiations. Journal of Evolutionary Biology, 23(8): 1581-1596. PMID: 20561138 DOI: 10.1111/j.1420-9101.2010.02029.x 